\title{
Attentional processes in posttraumatic stress disorder and the associated changes in
}

neural functioning

Authors: Stefanie R. Block ${ }^{123}$ and Israel Liberzon, MD ${ }^{123}$

Affiliations:

${ }^{1}$ Department of Psychiatry, University of Michigan, Ann Arbor, MI

${ }^{2}$ Department of Psychology, University of Michigan, Ann Arbor, MI

${ }^{3}$ VA Ann Arbor Health Care System, Ann Arbor, MI

\section{Correspondence to:}

Stefanie R. Block, M.S.

University of Michigan

Department of Psychology

2269 East Hall

530 Church Street

Ann Arbor, MI 48109

Phone: 734-232-0240

Email: srblo@umich.edu

Word Count: $8765+$ abstract (157)

Figures: 2

Tables: 5 


\begin{abstract}
Posttraumatic Stress Disorder (PTSD) is associated with alterations in attention at the behavioral and neural level. However, there are conflicting findings regarding the specific type of attention impairments present in PTSD, as the commonly used tests of attention do not isolate the mechanisms behind attention abnormalities, and the constructs measured do not map onto the neurocircuits governing attention. Here we review the literature on attention processing in PTSD and offer directions for future research to clarify these unanswered questions. First, using instruments that allow assessment of behavioral and neurophysiological attention components will be necessary to understand attention deficits in PTSD. Second, focus on intra-individual variability in addition to assessment of central tendency may help clarify some of the mixed findings. Third, longitudinal studies on attentional processes are warranted to determine how attention contributes to the development and maintenance of PTSD. Integration of behavioral and neural measures of attention will be useful in understanding the pathophysiology of PTSD.
\end{abstract}

Keywords: Attention; PTSD; Post-traumatic stress; intraindividual variability; neural networks; functional magnetic resonance imaging; cognitive ability; attentional bias; neuropsychological assessment; trauma 


\section{Introduction}

The fact that at $70 \%$ of the US population will experience a traumatic event in their lifetime is a sobering thought (Posttraumatic Stress Disorder (PTSD) Alliance, 2000). While many people recover from such experiences, up to $20 \%$ of people who experience a traumatic event develop Posttraumatic Stress Disorder (PTSD) (Posttraumatic Stress Disorder (PTSD) Alliance, 2000), a disorder characterized by intrusive thoughts, hyperarousal, avoidance, and emotional numbing (American Psychiatric Association, 2013), suggesting that there may be risk factors that make some more vulnerable to PTSD development following trauma exposure. While there are evidence-based treatments for PTSD, these are only effective in some individuals, while partially effective, not effective, or not accessible to others (Connor et al., 1999; Disorder et al., 2014; Hembree et al., 2003; Ipser et al., 2006). Thus, there is a great need to find new ways to provide better treatment for PTSD. Studying the neurobiological and cognitive processes associated with PTSD may help elucidate etiological risk factors and assist with the development of effective therapies. In particular, studying the role of attention in PTSD development carries great promise, as attention is a critical component of emotion regulation (Ochsner and Gross, 2005), a process that is dysregulated in PTSD (Frewen and Lanius, 2006).

Many independent lines of investigation have implicated attention abnormalities in PTSD. First and foremost, patients with PTSD describe symptoms of hyperarousal, concentration difficulties, and intrusive thoughts (American Psychiatric Association, 2013; VanElzakker, 2015), all of which may be related to attention abnormalities. For example, PTSD patients frequently report lapses of attention, difficulty focusing and 
becoming distracted (Lew, 2011). Second, there is high comorbidity between PTSD and Attention Deficit Hyperactivity Disorder (ADHD) (Spencer and Faraone, 2015). Third, PTSD patients display altered attention biases towards emotional stimuli (Pineles and Shipherd, 2009). Fourth, PTSD subjects have altered performance on neuropsychological tests of attention (Aupperle et al., 2012; Polak et al., 2012a; Qureshi et al., 2011). Finally, our lab among others, has found differences in neural networks related to attention in PTSD (Daniels et al., 2013; R. Sripada et al., 2012; R. K. Sripada et al., 2012).

There are also substantial conceptual and methodological gaps between the basic and the clinical research on attention in PTSD. First, there are conflicting research findings regarding the specific type of attention impairments present in PTSD, as neuropsychological tests commonly used in clinical settings do not isolate the physiological mechanisms behind attention abnormalities, and the constructs measured do not map onto the neurocircuits governing attention (Petersen and Posner, 2012). Second, key components of attention functioning might be left unaddressed by studies ignoring intra-individual variability in attention, a measure which has been shown to be more reflective of attention deficits than measures of central tendency such as mean reaction time (RT) and accuracy (Lew, 2011) . Third and finally, it remains unclear whether attention deficits are a risk factor or a consequence of the disorder. We have developed a program of research investigating the attentional processes in PTSD and associated changes in the underlying neural circuitry. Integrating these multiple lines of research may contribute to our understanding of the development and treatment of PTSD.

\section{What is Attention?}

According to William James, (James, 1890), 
"Everyone knows what attention is. It is taking possession of the mind in clear and vivid form of one out of what seem several simultaneous objects of trains of thought (pp. 381-382).”

While it may seem obvious what attention is, there are strikingly different definitions in the literature. The first set of definitions stems from the neuropsychology literature, while the second stems from the cognitive neuroscience literature.

Neuropsychology attempts to understand the relationship between behavioral impairments and brain disturbances using a battery of non-invasive tests. Interest in establishing these relationships began in the $19^{\text {th }}$ century when Paul Broca and Carl Wernicke, who were working with language impaired patients, identified specific areas of brain damage in these patients postmortem (Shallice, 1988). However, examining the brain postmortem is rarely feasible. Thus, tests developed by neuropsychologists have been a valiant effort to understand neurobiological processes underlying behavior without directly observing the brain itself. From this, largely functional and essentially hypothetical categories of attention have been postulated, which are still used in clinical neuropsychology today. In this domain (Sohlberg and Mateer, 1989), attention is categorized as focused (directing attention to one input) and divided (focusing on multiple inputs simultaneously). Focused attention is further categorized as sustained (attending to one specific task for continuous period of time), selective (focusing on one task while filtering out distractions) and alternating attention (switching focus back and forth between tasks with different demands).

While these distinctions appear to have face validity, they have not been shown to have distinct neurobiological underpinnings as once assumed. According to Patterson and Plaut, neuropsychology "has yielded relatively little advance in understanding how 
the brain accomplishes its cognitive business" ((Patterson and Plaut, 2009) p. 39). Newer research in cognitive psychology, has, however, established a model of attention that more closely maps neural functioning. According to Posner et al. (Posner and Petersen, 1990) attention consists of three components: alerting (maintaining a state of vigilance and attending to novel stimuli), orienting (shifting and focusing on a subset of inputs) and conflict monitoring/executive attention (attention to and resolving incongruent stimuli). Roughly speaking, sustained attention in neuropsychology nomenclature may be thought of as similar to what Posner calls alerting attention, while selective attention may be thought of as similar to what Posner calls orienting attention, however, depending on the object of focus, the clinical components of attention may involve any or all of Posner's components. For example sustaining one's attention on a task for a long period of time may require vigilance, repeatedly shifting and attention as distractions arise, and conflict monitoring to detect the stimuli of interest while ignoring the rest. While alerting is considered to be a stimulus-driven, bottom-up process, meaning that is automatic and reflexive, orienting attention is thought to be top-down, and volitional (Corbetta and Shulman, 2002). Either of these may be overt (involving a shift of the eyes) or covert (without eye shifting) (Fan and Posner, 2004). Subsequent studies have suggested that these three components likely have distinct neuroanatomy (Petersen and Posner, 2012) that will be discussed in detail in the next section.

\section{Neural circuitry of attention}

Functional magnetic resonance imaging (fMRI) studies suggest that the brain might be organized into multiple distinct intrinsic connectivity networks (ICNs), groups of brain regions (Figure 1), whose low frequency spontaneous blood-oxygenation-level- 
dependent (BOLD) activity fluctuates together (Raichle, 2011; Yeo et al., 2011).

Broadly speaking, these networks can be grouped into "task-positive," brain areas which are activated during tasks requiring external attentional control and "task-negative," brain areas which are deactivated during task performance, but are instead activated during "rest" a passive, day-dreaming like state (Power et al., 2011). There are three attentionrelated neural networks that are task-positive including the salience network/cinguoopercular network (SN), the ventral attention network (VAN), and the dorsal attention network (DAN) while there is one task negative network termed the default mode network (DMN) (Corbetta and Shulman, 2002; Ptak, 2012; Seeley et al., 2007), and finally there is one network, termed frontoparietal control network (FPCN), involved in the integration of information from both task positive and task negative networks (Markett et al., 2014).

[Insert Figure 1 here; 1.5 column width].

These networks serve distinct, but related functions in the control of attention. First, the $\mathrm{SN}$, anchored in the anterior insula (AI), amygdala, and dorsal anterior cingulate cortex (dACC), is involved in detecting salient stimuli and in signaling the need to switch from a state of rest to a state of task performance and is activated during conflict monitoring tasks (Menon and Uddin, 2010). The VAN, anchored in the right inferior frontal gyrus and right temporoparietal junction, is involved in maintaining tonic alertness and detecting unexpected warning cues (Corbetta and Shulman, 2002). Some investigators suggests that the SN and VAN might be partially overlapping networks (Kucyi et al., 2012; Yeo et al., 2011), although other research shows that they are distinct (Sadaghiani and D'Esposito, 2014). The DAN, anchored in the frontal eye fields, 
dorsolateral prefrontal cortex, and superior parietal lobe, is involved in selective visual and spatial attention (Corbetta and Shulman, 2002). The DMN, anchored in the ventromedial prefrontal cortex and posterior cingulate cortex is involved in states of rest that do not involve exogenous attention to the environment (Buckner and Vincent, 2007). Lastly, the FPCN, anchored in the lateral and dorsal medial prefrontal cortex and the posterior parietal cortex (anatomically between the DAN and DMN), is involved in working memory and guiding goal directed behavior by integrating information from both task-positive and negative networks (Markett et al., 2014). The parcellation of these networks was originally described using functional connectivity, a method which examines the degree to which different brain area's low frequency BOLD activity correlates with one another over time (Yeo et al., 2011), however, other neuroimaging approaches such as task-induced activations have shown that the three components of Posner and Peterson's triparte model of attention - alerting, orienting and conflict monitoring - activate regions of the VAN, DAN and SN, respectively (Fan et al., 2005). The attention components all also modulated by different neurotransmitters systems, mainly, noradrenergic, cholinergic and dopaminergic, respectively (Petersen and Posner, 2012).

\section{Attention Deficit Hyperactivity Disorder and PTSD}

One of the strongest pieces of evidence for attention difficulties in PTSD is the high comorbidity with ADHD (Daud and Rydelius, 2009), a disorder characterized by impulsivity, inattentiveness and hyperactivity (American Psychiatric Association, 2013). This association between PTSD and ADHD goes beyond trauma exposure, or the association seen in general psychiatric illness. In fact, one study found that behavioral 
performance in those with ADHD was indistinguishable from those with PTSD on a battery of attention tasks (Armengol, 2003). A recent meta-analysis of 22 studies found that in samples of ADHD, the risk of developing PTSD was four times greater than nontrauma-exposed control (NTC) samples (Spencer and Faraone, 2015). Similarly, in samples of PTSD, the risk of having ADHD was twofold that of controls with similar levels of trauma exposure (Spencer and Faraone, 2015). The relative risk was still significantly higher even when compared to psychiatric populations such as oppositional defiant disorder, mood disorders, antisocial personality, substance use disorders and panic disorder (Spencer and Faraone, 2015). This meta-analysis included studies that used structured diagnostic assessments, included adequate control samples (e.g. nonADHD), and had a primary focus on the relationship between ADHD and PTSD.

The literature suggests that the link between ADHD and PTSD might be bidirectional. First, ADHD may constitute a risk factor for developing PTSD. Because, ADHD is an early onset psychological disorder, it often precedes PTSD diagnosis. Those with ADHD also have difficulty with impulse control, focusing, and stress management (Szymanski et al., 2011), and are more likely to be perceived as defiant, noncompliant, and aggressive (Monastra, 2008). Due to their impulsive behavior, they may be more likely to experience traumatic events (Szymanski et al., 2011). ADHD may also affect the way that fear memories are consolidated (Adler et al., 2004; Storm and White, 2010), and neurobiological circuits which make one more vulnerable to develop PTSD.

In concert, PTSD may also constitute a risk factor for developing ADHD. For example, trauma-exposed children tend to have trouble regulating anger and difficulty self-soothing (Luxenberg et al., 2001). Trauma may affect the ability of children to 
express their emotions, resulting in acting out through externalizing behaviors (Szymanski et al., 2011). Symptoms of PTSD may manifest as ADHD or be misdiagnosed as ADHD in children. Specifically, avoidance symptoms may manifest as inattentive ADHD symptoms, hyperarousal as hyperactivity, and intrusive symptoms as difficulty listening (Shucard et al., 2008). As we will discuss later, PTSD may also affect the neurobiological circuits related to attention, which make one more vulnerable to develop ADHD. To fill the gap in our knowledge of how these two disorders influence one another, future research should examine the common genetic and neurobiological circuits of these disorders, as well as examine longitudinally how specific symptoms confer risk factors at different developmental periods (Spencer and Faraone, 2015).

\section{Affective Measures of Attention in PTSD}

Cognitive-behavioral models of PTSD pathophysiology suggest that a bias to attend to threatening information might contribute to the development and maintenance of PTSD symptoms (MacLeod et al., 1986; Mogg and Bradley, 1998). Numerous studies have indeed found disrupted attention to affective stimuli in PTSD (Bardeen and Orcutt, 2011; Beck and Freeman, 2001; Beevers and Lee, 2014; Bryant and Harvey, 1997;

Constans and McCloskey, 2004; Dalgleish and Moradi, 2001; Elsesser et al., 2004; Fani et al., 2012; Fleurkens et al., 2011; Foa et al., 1991; Harvey et al., 1996; KhouryMalhame and Lanteaume, 2011; Kimble et al., 2010; McNally and Kaspi, 1990; Moradi et al., 1999; Pine and Mogg, 2005; Pineles and Shipherd, 2009; Pineles et al., 2007; Sipos and Bar - Haim, 2014; Stanford et al., 2001; Vrana et al., 1995; Vythilingam and Blair, 2007; Wald et al., 2011) (Table 1), however, there is debate over the underlying mechanisms of this disruption. 
[Insert Table 1 here. Double column width].

Attentional biases are defined as quicker RT to respond to stimuli of one affect over another. For example, in the dot-probe (MacLeod et al., 1986) paradigm, two affective stimuli appear for a short duration on either side of the screen, after which, one is replaced by a target stimulus (usually an arrow or a letter). Faster RT to targets presented in the same location at threatening stimuli are interpreted as a bias towards threat (Bryant and Harvey, 1997), a phenomenon that has been observed repeatedly in PTSD (Bardeen and Orcutt, 2011; Bryant and Harvey, 1997; Constans and McCloskey, 2004; Dalgleish and Moradi, 2001; Elsesser et al., 2004; Fani and Bradley-Davino, 2011; Fani et al., 2012; Khoury-Malhame and Lanteaume, 2011; Pine and Mogg, 2005; Sipos and Bar - Haim, 2014; Wald et al., 2011). Similar paradigms include the emotional lexical decision task (Vythilingam and Blair, 2007), in which participants must judge whether a series of letters (some of which form emotional words) is a real word or a nonword (faster RT to emotional words indicates an attention bias) and the modified-Stroop (Williams et al., 1996), which presents affective or trauma related words in addition to the classical color words. For the latter, if a participant displays greater inference to threatening words than to neutral words (longer RT to state the color of the word), he/she is said to have an attentional bias towards threat, a pattern that has been observed in PTSD on this task (Beck and Freeman, 2001; Fleurkens et al., 2011; Foa et al., 1991; Harvey et al., 1996; McNally and Kaspi, 1990; Moradi et al., 1999; Paunovic et al., 2002; Vrana et al., 1995; Vythilingam and Blair, 2007).

\section{Facilitated Orienting vs. Difficulty with Disengagement}


While the evidence is clear that PTSD is associated with attentional biases, the most commonly used paradigms are not able to isolate the mechanisms underlying altered performance (Weierich et al., 2008a). Faster RT on trials with affective stimuli can be interpreted as facilitated orienting towards threat, however, faster RT on these trials could also stem from difficulty in disengaging from the emotional stimuli (Weierich et al., 2008a). Studies of individuals with trait anxiety and college students with posttraumatic stress symptoms have reported dot-probe biases that are more consistent with difficulty disengaging attention than increased vigilance towards threat (Bardeen and Orcutt, 2011; Salemink et al., 2007), however, it is unknown whether this would also be true of individuals with PTSD. A recent meta-analysis of the emotional-Stroop studies in PTSD and anxiety disorders suggest that enhanced interference, seen on these tasks is more consistent with disengagement than facilitated orienting (Phaf and Kan, 2007). In concert, Vrana et al., (Vrana et al., 1995) found that compared to trauma exposed controls (TEC), those with PTSD had better memory for emotional words than neutral words on an emotional-Stroop task, suggesting that they probably spent longer time processing this information, consistent with the difficulty disengaging.

Eye-tracking, visual-search paradigms, and the detection of target (DOT) tasks that use threat-related stimuli, are able to distinguish between facilitated orienting vs. disengagement difficulty, and the findings suggest that both of these processes may be affected in PTSD. Using eye tracking, Felmingham et al. (Felmingham and Rennie, 2011) found that PTSD patients had a significantly greater number of initial visual fixations to trauma words suggesting facilitated orienting towards threat In concert, Kimble et al. (Kimble et al., 2010) showed that veterans with high levels of PTSD 
symptoms compared to veterans with low levels of symptoms attended to trauma-related images prior to neutral ones and had greater pupil dilation when viewing trauma-related images, reflecting a greater sympathetic nervous system activation to these images. Together, this supports the idea that those with PTSD may have greater initial vigilance towards threatening information than those without PTSD. On the other hand, the latter study also found that those with higher levels of PTSD symptoms spent greater mean time viewing the trauma-related images compared to neutral, supporting the idea that those with PTSD have difficulty disengaging attention. Visual search paradigms have also found more evidence for difficulty disengaging from threat. In such paradigms, the person is instructed to identify a target as quickly as possible amongst and array of distracters (Fleurkens et al., 2011). The speed of identification reflects the efficiency for orienting attention to that target. Pineles et al. (Pineles and Shipherd, 2009) showed that sexual assault survivors with high levels of PTSD symptoms were no faster than those with low levels of PTSD symptoms at detecting trauma-related words, but instead they had difficulty disengaging from trauma reminders. In an earlier study (Pineles et al., 2007), this group also found evidence for disengagement difficulties, but no support for facilitation of threat processing in veterans on a visual search task. Using the DOT task, a paradigm similar to the dot-probe which yields measurements of both orienting and disengagement, El-Khoury et al. (Khoury-Malhame and Lanteaume, 2011) also found support for disengagement problems in PTSD. In summary, facilitated orienting towards threat as well as difficulty disengaging from threat may be mechanisms for attentional abnormalities in PTSD.

\section{Avoidance}


Biases towards threat, however, are not the only finding emerging from studies with affective stimuli in PTSD. Some studies have reported slower RT to negatively emotional stimuli, and consequently quicker RT to positively valenced or neutral stimuli. For example, a bias away from angry faces was associated with greater levels of abuse and PTSD symptoms in maltreated children (Pine and Mogg, 2005), while adults with a history of maltreatment were shown to have a bias towards happy faces (Fani and Bradley-Davino, 2011). Slower RT to negative stimuli, interpreted as avoidance of such stimuli, has also been supported by two longitudinal studies. Beevers et al. (Beevers and Lee, 2014) found that bias away from fearful faces prior to deployment predicted PTSD symptoms in war-exposed soldiers. Similarly, Wald et al. (Wald et al., 2011) found that Israelis who had a bias away from threatening words on a dot-probe task, were more likely to develop PTSD symptoms within a year from war exposure than those who did not have this bias. Bias away from threat may be modulated by severity of traumaexposure, as it predicts PTSD symptoms in recently traumatized individuals (Elsesser et al., 2004), those with chronic PTSD (Elsesser et al., 2004), and recently returning veterans with high levels of combat exposure (Sipos and Bar - Haim, 2014). Thus, an interaction between trauma-severity and threat avoidance may confer a risk for developing PTSD.

\section{Reconciling Attention Bias Findings}

Two main hypotheses have been posited to reconcile these seemingly contrasting findings that populations with trauma, stress and anxiety-related disorders are associated with both biases towards and away from threat, termed the vigilance-avoidance (VA) hypothesis and the attention-maintenance (AM) hypothesis (Weierich et al., 2008b). 
According to the VA hypothesis, some individuals initially overtly attend towards and process threat-related information more effectively, consistent with hypervigilance symptoms observed in PTSD, but then subsequently avoid threat in order to prevent negative affect. This process may occur because rapid identification of threat is an adaptive coping strategy to survive a state of danger. In the long term, however, avoidance is maladaptive because individuals lose opportunities to habituate and reappraise the situation, leading to the maintenance of PTSD symptoms (Weierich et al., 2008a). Indeed, avoidance is a core symptom cluster of PTSD (American Psychiatric Association, 2013), with treatment models such as prolonged exposure, hinging on the principles of exposure and habituation (Powers et al., 2010). In this way, reducing avoidance to the fear memory allows for habituation of the fear response.

According to the AM hypothesis, in contrast, there is no difference in the orienting of overt attention towards threat, however, threatening stimuli captures attention in a way that makes it difficult to disengage, which may increase rumination and anxiety consistent with intrusive and hyperarousal symptoms observed in PTSD (Weierich et al., 2008b). Although these two hypotheses may seem conflicting, Weierich et al. (Weierich et al., 2008a) suggested that they might be complimentary to one another. They hypothesize that depending on the timescale of the event, anxiety is characterized by hypervigilant scanning for a threatening target (VA hypothesis), longer fixation of this target (AM hypothesis), followed by avoidance of the target once the person is able to disengage (VA hypothesis). This may explain why all three processes have been observed in PTSD.

\section{Neural Correlates of Attention Biases}


Neuroimaging studies in PTSD implicate multiple neural networks in attention biases and have provided further support for altered orienting, disengagement and avoidance (Table 2). Imaging studies examining the dot-probe task in PTSD have found evidence for increased activation of attention regions to emotional stimuli, possibly reflecting hypervigilance or difficulty disengaging. For example, Fani et al. (Fani et al., 2012) found that PTSD had greater DAN and FPCN activation compared to TEC and that threat bias was correlated with greater DAN activity, while avoidance was correlated with greater VAN and SN activity. Similarly, Thomaes et al. (Thomaes et al., 2013) found greater VAN activity to emotional distractors on a working memory task.

In contrast to these findings, imaging using the emotional-Stroop paradigm has found decreased activation in a variety of attention related regions. This finding is less surprising, however, since Kimble et al. (Kimble et al., 2009) found little evidence for the presence of an attention bias towards threat in this task. Blair et al. (Blair and Vythilingam, 2013) reported decreased DAN and VAN activation to emotional stimuli compared to NTC and TEC, consistent with Bremner et al. (Bremner et al., 2004) who reported decreased blood flow to the DAN and SN using positron emission tomography (PET) in PTSD compared to TEC. Additionally, Shin and colleagues (Shin et al., 2001) reported decreased rostral ACC activity in veterans with PTSD compared to combat veterans. These results may be a reflection of avoidance of emotional stimuli. However, in a study of people with subthreshold PTSD (White et al., 2015), those with greater symptoms had greater SN, VAN and DAN activation, though this could reflect differences in the study population. It's possible that greater activation of these regions is a compensatory mechanism for those exposed to trauma who do not develop PTSD, as 
Blair et al. (Blair and Vythilingam, 2013) actually found greater DAN activation in TEC compared to PTSD and NTC on the emotional-Stroop. As described earlier, however, measures of attentional biases on both the dot-probe and emotional-Stroop tasks can reflect facilitated-orienting, disengagement and avoidance, thus making the interpretation of these imaging findings difficult.

[Insert Table 2 here. Double column width].

Further studies have attempted to disentangle these questions. On an emotional oddball task, Hayes et al. (Hayes et al., 2009) reported that those with higher levels of PTSD symptoms had more DAN, DMN, and SN activity to emotional distractors compared to those with low levels of symptoms, but decreased VAN activity. On the other hand, they also found that those with greater PTSD symptoms had less DAN and SN activity to neutral targets. The authors suggest that in the absence of emotional stimuli, the attentional networks may be increased in PTSD due to hypervigilance, but during the presence of emotional stimuli, these regions are preferentially activated towards the processing of emotion. This has been further supported by Morey et al. (Morey et al., 2008), who found that greater PTSD symptoms were positively correlated with greater VAN and DMN activity to viewing combat compared to civilian images, but negatively correlated with activity in the DAN, SN and VAN during an executive identification task interleaved with emotional pictures. This was also supported by Stanford et al. (Stanford et al., 2001), who reported that PTSD subjects had greater eventrelated potential (ERP) responses to trauma-related stimuli, but attenuated ERP responses to neutral targets and non-trauma relevant stimuli. Finally, one neuroimaging study (Khoury-Malhame and Reynaud, 2011) has examined the DOT task, finding that that 
amygdala activity was positively associated with the disengagement index, suggesting that attentional regions, such as the $\mathrm{SN}$, may intrude upon other networks during attentional processing.

\section{Summary}

In summary, attention towards emotional stimuli may be affected in PTSD. Facilitated orienting, difficulty disengaging, and a lack of attention towards threat through avoidance are all observed in PTSD, however, the findings differ based on the tasks used. In addition, all of the neural networks involved in attention have been implicated in these cognitive processes, however, the results differ based on the paradigms, and thus further research is needed in this area, highlighting the heterogeneity of PTSD and the role of context in threat processing.

\section{Non-Affective Measures of Attention}

\section{Traditional Neuropsychological Tests}

Clinically, attention has been assessed using a battery of neuropsychological tests, in which longer RTs and decreased accuracy reflect deficits in attention (Table 3). Earlier reviews (Aupperle et al., 2012; Horner et al., 2002) and two more recent metaanalyses of cognitive functioning in PTSD (Polak et al., 2012a; Qureshi et al., 2011) have all found evidence for attentional impairments based on these measures, while evidence for impairments in other cognitive domains, such as memory, learning, and visuospatial functioning is much weaker.

Although many neuropsychological tests are purported to measure attention, they do not effectively isolate the measurement of attention from that of other executive functions (Brock and Clinton, 2007; Perry and Hodges, 1999). One such example are 
memory span tests (e.g. digits span), which ask the participant to immediately repeat a list of items he/she just saw or heard (Wechsler, 2008)(Wechsler, 2009). Some studies have found PTSD participants to be impaired on these tests (Koenen et al., 2001a; Polak et al., 2012a; Samuelson et al., 2006; Vasterling et al., 2002)(Steudte-Schmiedgen, 2014), while others have not (Burriss et al., 2008; Gil et al., 1990; Gilbertson and Paulus, 2006; Neylan et al., 2004; Twamley et al., 2004a; Uddo et al., 1993). While attention is required to complete these tasks, they also involve working memory, which is functionally and neuroanatomically distinct from attention (Awh et al., 2006). Thus deficits on these tasks may reflect memory deficits and not attention. This was supported by La Garde et al. (LaGarde et al., 2010) and Johnsen et al. (Johnsen and Asbjørnsen, 2008), who only found PTSD participants to have deficits on the backward digit span, which requires greater working memory. A similar story is found with tests that are purported to measure alternating attention (e.g. the Wisconsin Card Sort Task (BERG, 1948), the Tower of London (Krikorian et al., 1994), the Trail Making Test Part B (TMTB) (Reynolds, 2002), and the digit symbol test (Wechsler, 2008)). While some authors have used impairments on these tests to implicate attention deficits in PTSD (Gilbertson and Paulus, 2006; Gurvits, 2000; Jenkins and Langlais, 2000; John Hart et al., 2008; Kivling-Bodén and Sundbom, 2003; Koso and Hansen, 2006a; LaGarde et al., 2010; Polak et al., 2012b; Stein et al., 2002; Sutker and Winstead, 1991), (Brandes et al., 2002a), the findings can implicate deficits in other domains besides attention such as planning, cognitive flexibility and set shifting, and a number of studies have failed to find impairments in PTSD (Kanagaratnam and Asbjørnsen, 2007; LaGarde et al., 2010; Twamley et al., 2004b; Vasterling et al., 2002), (Gil et al., 1990), (Steudte-Schmiedgen, 
2014). Finally, tests of processing speed, such as The Trail Making Test Part A (TMT-A) (Reynolds, 2002) in which the subject must connect a series of dots as quickly as possible without sacrificing accuracy, are purported to measure visual attention, but do not isolate the measurement of attention from that of processing speed, which may be independent of attention (Shanahan and Pennington, 2006). While two studies have found impairments in PTSD on this test (Koso and Hansen, 2006b; Sutker et al., n.d.), a number of others have not (Jenkins and Langlais, 2000; Koenen et al., 2001b; LaGarde et al., 2010; Stein et al., 2002; Twamley et al., 2004b). Therefore, the mixed results in this area may reflect the difficulty in parsing these two constructs apart. In sum, many studies suggest PTSD impairments on these neuropsychological tasks; however, the mechanisms underlying the impairments remain unclear.

[Insert Table 3 here. Double column width].

A further limitation with neuropsychological tests is that the constructs measured (divided vs focused - sustained, selective, and alternating) do not correspond to the underlying neuroanatomy of attention, and thus impairments on these tests do not pinpoint specific neural deficits. For example, the division between divided and focused attention is not well supported neuroanatomically (Hahn et al., 2006). Furthermore, the same tasks (TMT-B, Paced-Auditory-Serial-Addition-Test, digit symbol) that are used to measure divided attention are also are purported to measure alternating and sustained attention (Bennett, T., Raymond, M., Malia, K., Bewick, K., \& Linton, 1998)(Jenkins and Langlais, 2000). While all but one study (Gil et al., 1990) has found PTSD subjects to have performance deficits on these tasks (Gurvits, 2000; Jenkins and Langlais, 2000; John Hart et al., 2008; Koenen et al., 2001a; Koso et al., 2012; LaGarde et al., 2010; 
Polak et al., 2012b; Stein et al., 2002), the interpretation of these findings is challenging as deficits on these tasks do not shed any further light on specific neural circuits that may be affected in PTSD.

Cognitive functioning in other domains (memory, learning, etc.) is beyond the scope of this review. While deficits in other cognitive domains have been reported (Bremner et al., 2004; Vasterling et al., 2002; Yehuda et al., 2004), studies examining these components do not always control for attention functioning (Qureshi et al., 2011). Therefore, it is possible that attention deficits account for these findings, as attention is a requirement for effective memory encoding, learning and retrieval (Qureshi et al., 2011).

Continuous Performance Tasks (CPTs) and response inhibition tasks, on the other hand, are more robust tests for assessing attention deficits. During a CPT, a series of stimuli are presented rapidly and the subject must respond to a target that occurs in low frequency, which requires attention over prolonged periods of time. CPTs are often used in assessing attention in classical attention-related disorders like ADHD (Greenberg and Kindschi, 1994). A number of studies have reported increased RT (McFarlane et al., 1993) and decreased accuracy (Bellis et al., 2013; Koso and Hansen, 2006a; Semple et al., 1996; Shucard et al., 2008; Vasterling et al., 1998, 2002) in PTSD subjects. However, Golier et al. (Golier et al., 1997) reported that PTSD subjects only made more commission errors at a trend level, while Stein et al. (Stein et al., 2002) and Gil et al. (Gil et al., 1990) reported that PTSD subjects, TEC and psychiatric controls were all impaired compared to healthy controls, but not significantly different from each other. Furthermore, some studies (Crowell et al., 2002; Eren - Koçak and Kılıç, 2009; Johnsen and Asbjørnsen, 2008; Lagarde et al., 2010; Lindauer et al., 2006; Twamley et al., 2004b; 
Zalewski et al., 1994) have failed to find evidence for CPT deficits in PTSD. These discrepancies may reflect differences in sample size, study population and PTSD severity. CPTs can require alerting, orienting and conflict monitoring, and mixed findings may reflect the fact that PTSD subjects are impaired only in specific areas of attention, but not all three. As a whole, CPTs suggest that attention may be affected in PTSD, but do not isolate the specific type of attention impaired. Selective attention on a task requires inhibition of prepotent/inappropriate responses (Posner, 1980), and indeed, a number of studies have found PTSD subjects to be impaired on response inhibition tasks such as the Haylin Sentence Completion Task (Koso and Hansen, 2006b), the Go/No-Go Task (Wu et al., 2010), and the Stop Completion Task (Casada and Roache, 2005). For example, Wu et al. (Wu et al., 2010) reported that PTSD subjects made more commission errors on No-Go trials compared to controls, showing that they had difficulty inhibiting their automatic responses. In turn, PTSD subjects were faster on Go-trials reflecting a speed-accuracy trade-off. Additionally, Shucard et al. (Shucard et al., 2008) reported that veterans with PTSD had longer P3 latency and greater frontal P3 amplitude to No-Go and non-target stimuli than controls using ERP. Furthermore, these ERP components were associated with hyperarousal and re-experiencing symptoms. These findings suggest that, PTSD subjects may have difficulty inhibiting appropriate responses and filtering out non-relevant information.

Ecologically, deficits in response inhibition may manifest as impulsivity, which has been broadly defined as "action without foresight" (Winstanley et al., 2006), and is core diagnostic feature of ADHD (American Psychiatric Association, 2013). Supporting this link are findings that individuals with ADHD manifest response inhibition deficits on 
tasks such as the Go/No-Go and Stop-Signal Tasks (Patros et al., 2015). Not surprisingly, PTSD and trauma exposure have also been associated with greater impulsivity, further supporting the role of attention deficits in this disorder (Netto et al., 2016). For example, PTSD has been linked to increases in reckless driving (Lapham et al., 2006), risky sexual behavior (Green et al., 2005), substance use (Jakupcak et al., 2007), self-harm (Kimbrel et al., 2014) and aggressive behavior (Jakupcak et al., 2007). Furthermore, the significance of impulsivity in PTSD was highlighted by the addition of the symptom "reckless behavior that may lead to accidental injury to self or others, thrill seeking, or high risk behaviors" (American Psychiatric Association, 2013) in the latest edition of the Diagnostic and Statistical Manual of Mental Disorders.

\section{Evidence for Behavioral Deficits According to Posner Model}

In contrast to the neuropsychological literature, there are a number of tests from the cognitive psychology literature (Eriksen and Eriksen, 1974; Fan et al., 2002; Greene et al., 2008; Posner, 1980; Simon and Wolf, 1963; Stroop, 1935) which isolate alerting, orienting, and conflict monitoring according to Posner and Peterson's (Posner and Petersen, 1990) triparte model of attention, which more closely reflects neural circuits of attention (Petersen and Posner, 2012) and therefore, may be more informative in understating attention deficits in PTSD (Table 4). The only one which measures and isolates all three is the Attention Network Task (ANT; See Figure 2) (Fan et al., 2002), which is a combination of the Posner Cueing Task (Posner, 1980) and the Eriksen Flanker Task (Eriksen and Eriksen, 1974). It has been used in a wide variety of populations including children, older adults, individuals with psychiatric disorders, and non-human primates (Adólfsdóttir et al., 2008; Beran et al., 2003; Gooding et al., 2006; 
Jennings et al., 2007). Originally, it was found to have high test-retest reliability, $r=$ 0.87 (Fan et al., 2002), but a more recent study found lower split-half reliabilities for the three networks, in addition to small correlations between the three networks, suggesting they are not completely independent (Macleod et al., 2010). However, we are not aware of any superior tests to simultaneously measure these attention components. Since the evidence using the ANT in PTSD is limited to date, we also have tried to address the implications of other findings reported in PTSD related to the alerting, orienting and conflict monitoring components of attention.

[Insert Figure 2 here. Single column width].

\section{Alerting}

There is little evidence for deficits in alerting attention, the ability to maintain a state of vigilance and attend to novel stimuli, in PTSD. On the ANT, the alerting component is isolated by comparing the RT during trials when there is a temporal warning signal to trials without a temporal warning signal. Only three studies have examined ANT performance in PTSD, with none finding impairments in alerting in PTSD (Leskin and White, 2007), (Ogden, 2010), [Block et al., under review]. BarlowOgden et al. (Ogden, 2010) reported that there were only alerting deficits in a PTSD group that also had traumatic brain injury (TBI). Alerting is likely required in most neuropsychological tests, but may be most taxed in sustained attention tasks, such as CPTs and memory span, but as stated earlier the evidence for deficits in PTSD is mixed. Furthermore, CPT and memory span performance may reflect deficits other than alerting.

\section{Orienting}


Orienting is the ability to shift attention and focus on a subset of inputs (Posner, 1980). Again, it is likely involved in numerous neuropsychological tests, most clearly the Trail Making and digit symbol tests, as the person must visually scan information and move his/her attention to a new spatial location. Interestingly, while impairments for TMT-A are mixed (Jenkins et al., 2010; Koenen et al., 2001b; Koso and Hansen, 2006b; Lagarde et al., 2010; Stein et al., 2002; Sutker et al., n.d.; Twamley et al., 2004b), all studies using TMT-B found impairments in PTSD (Gurvits, 2000; Jenkins and Langlais, 2000; John Hart et al., 2008; Koenen et al., 2001a; Koso and Hansen, 2006a; Lagarde et al., 2010; Polak et al., 2012b; Stein et al., 2002; Sutker et al., n.d.) and most studies employing the digit symbol test were positive for PTSD-specific deficits (Brandes et al., 2002b; Jenkins and Langlais, 2000; John Hart et al., 2008; Parslow and Jorm, 2007). These findings suggest that orienting attention may be impaired in PTSD. However, on tests that directly isolate orienting attention (Posner cueing task; ANT), the findings in PTSD have been mixed. On these tests, orienting is isolated by comparing the RT during trials when there is a spatial warning signal to trials with a neutral warning signal. In a sample of veterans with PTSD, we found [Block et al., under review] deficits in orienting attention, driven by difficulty disengaging attention from a location where target arrows did not appear. Similarly, Pacheco-Unguetti et al. (Pacheco-Unguetti et al., 2011) found that patients with anxiety disorders (including PTSD) had greater orienting effects relative to controls, which were driven by greater RT to invalidly cued targets. These findings extend that of the attention bias literature to show that disengagement of attention may be an issue even with non-emotional stimuli. In contrast, Leskin et al. (Leskin and White, 2007) and Jenkins et al. (Jenkins and Langlais, 2000) did not find 
orienting deficits in PTSD, while Odgen-Barlow et al. (Ogden, 2010) only found a PTSD+TBI group to have orienting deficits. Between-study differences with regard to the participants (e.g., age, gender, symptom and TBI severity) could potentially account for the observed differences. Moreover, the smaller group size in these studies (Leskin and White, 2007), (Jenkins and Langlais, 2000) could have reduced their power to detect group differences with regard to orienting attention. Another possibility is that orienting attention deficits are related to trauma exposure generally and are not specific to PTSD. Clearly, additional research will be needed to clarify the nature of orienting attention deficits in PTSD.

\section{Conflict Monitoring}

Impairments in conflict monitoring, or the detection of and resolution of incongruent stimuli in the environment, in PTSD has been mixed. In addition to the ANT, there are a number of tasks that isolate this process, such as the Stroop (Stroop, 1935) and Simon (Simon and Wolf, 1963) tasks, which compare the RT to respond to a target that is surrounded by incongruent flankers to a target that is surrounded by congruent flankers, termed the interference or conflict effect. A recent meta-analysis found PTSD subjects to be impaired on the Stroop task (Polak et al., 2012b), while more recently, Steudte et al. (Steudte-Schmiedgen, 2014) did not find any differences in the interference effect in the Simon Task. For the ANT, we did not find any differences between the PTSD and control group for conflict monitoring [Block et al., under review]; however, Leskin et al. (Leskin and White, 2007) found PTSD subjects to have a larger interference effect than both trauma and non-trauma exposed controls.

[Insert Table 4 here. Double column width]. 


\section{Summary}

In sum, non-affective tests of attention have provided evidence that overall attention performance is impaired in PTSD, however, they have not been able to establish which components of attention are affected. At present, the evidence suggests that orienting attention and conflict monitoring may be affected in PTSD, with impaired response inhibition and disengagement possibly contributing to these findings. The evidence for alerting attention is weaker, but cannot be ruled out. Examining neural circuitry might help elucidate these questions, which would be important in understanding how specific PTSD symptoms may be related to attention, thus providing a basis for examining novel treatments.

\section{Neural correlates of non-affective attention tasks in PTSD}

It has been proposed that alerting and orienting attention are subserved by the VAN and DAN accordingly (Fan et al., 2005), while disengagement may involve both networks (Thiel et al., 2004), as they are involved in maintaining a state of tonic alertness, the volitional shifting of visual attention and the reorienting of attention (Corbetta and Shulman, 2002). No PTSD neuroimaging studies have isolated these processes in order to study their neural correlates (e.g. there are no imaging studies using the ANT in PTSD), however, a few studies have implicated alterations of the VAN and DAN in other attention tasks (Table 5). Three studies have found decreased activation (fMRI) and blood flow (PET) to VAN regions in PTSD subjects during oddball (Felmingham et al., 2009), Go-No/Go (Falconer and Bryant, 2008) and Stroop tasks (Bremner et al., 2004). In contrast, Bryant et al. (Bryant et al., 2005) found greater VAN activation during an auditory oddball paradigm. Additionally, two of these studies (Bryant et al., 2005; 
Falconer and Bryant, 2008) found that PTSD subjects had greater visual, sensory and motor processing activation, which the authors speculated could have interfered with their ability to maintain attention. There are fewer studies implicating the DAN in PTSD during non-affective attention tasks. Bryant et al. (Bryant et al., 2005) reported PTSD subjects had decreased right dorsal middle frontal gyrus activation during an auditory oddball task, while the same group (Felmingham et al., 2009) later found increased activity in a similar, but more posterior area. Both studies consisted of relatively small sample sizes, requiring further replication. As behavioral studies point to possible orienting and disengagement deficits in PTSD, which are carried out by these neural networks, further neuroimaging research using tasks that isolate alerting and orienting are needed.

[Insert Table 5 here. Double column width].

More research has implicated abnormalities of the SN in PTSD, a network involved in conflict monitoring (Fan et al., 2005) (Table 5). The dACC (Bryant et al., 2005; Felmingham et al., 2009; Shin et al., 2007; Thomaes et al., 2012), AI (Thomaes et al., 2012), and amygdala (Bryant et al., 2005; Semple et al., 2000) have been shown to be hyperactive across a variety of attention paradigms including the Stroop (Shin et al., 2007; Thomaes and Dorrepaal, 2012), Multisource interference task (VanElzakker, 2015), auditory oddball tasks (Bryant et al., 2005; Felmingham et al., 2009) and CPTs (Semple et al., 2000), which may intrude upon other neural network's ability to carry-out taskrelated goals. VanElzakker et al. (VanElzakker, 2015), however, found that dACC hyperactivity was also present in non-traumatized twins of those with PTSD, suggesting that dACC hyperactivity may be a risk factor for developing PTSD. Abnormal SN 
connectivity has also been implicated in PTSD. At rest, when participants are not actively engaging in an attention task, PTSD subjects have greater connectivity within the SN and greater cross-network connectivity with task-negative regions, further suggesting that the SN may intrude upon other networks (Rabinak et al., 2011; R. Sripada et al., 2012; R. K. Sripada et al., 2012). We have also found PTSD subjects to have greater SNDAN resting-state connectivity compared to healthy controls [Block et al. under review]. In sum, there is strong evidence implicating SN abnormalities in PTSD, with mixed evidence for VAN and DAN alterations. Studies which combine activation, connectivity, and behavioral measures in addition to measuring multiple domains of attention may further our understanding of the roles of these ICNs in PTSD.

\section{Performance Variability}

A further source for inconsistent findings regarding attention performance in PTSD, may lay in intra-individual variability in PTSD patients. In most attention studies, measures of central tendency, such as mean RT and accuracy are examined for group differences (e.g. RT on Stroop task; commission errors on an oddball task). However, these tests assume that the variance within each group is relatively equal (MacDonald et al., 2006). Measures of central tendency do not capture the fact that while two groups may have the same mean, they may not have the same range or spread. Examining only the average may mask group differences in dispersion (MacDonald et al., 2006). Newer research (Coghill et al., 2013; MacDonald et al., 2006; Vaurio et al., 2009) suggests that measures of intra-individual variability (IIV; an individual's variability within a single session) may be a more distinguishing marker of an attentional impairment than measures of central tendency, such as the group mean, since people with larger IIVs are less 
consistent in their RTs. On a simple RT task, for example, someone with large IIV would at times have quick responses (e.g. $400 \mathrm{~ms}$ ), but at other times very slow responses (e.g. $1000 \mathrm{~ms}$ ), such that on average his/her mean RT of $700 \mathrm{~ms}$ would be the same as another individual whose range of RT only varied between 600 and $800 \mathrm{~ms}$. In other words, the person with the larger IIV would be less consistent across trials. This is thought to reflect lapses of attention and difficulty maintaining vigilance on the task at hand (Coghill et al., 2013; MacDonald et al., 2006; Vaurio et al., 2009). Failure of topdown attentional-control networks to suppress task-irrelevant distractors could result in larger IIV. Such distractors could be external (e.g. loud noise) or internal (e.g. intrusive thought), taxing the alerting and orienting systems, or incongruent to the object of focus (e.g. left-pointed-target arrow surrounded by right-pointed arrows) taxing the conflict monitoring system. IIV has already been well established as a marker of ADHD. For example, it is a scoring criteria of the T.O.V.A., a continuous performance test used in the diagnosis of ADHD (Greenberg and Kindschi, 1994). A meta-analysis of neuropsychological tests in ADHD found that IIV was the best discriminator between healthy and ADHD groups, while little additional predictive value was gained from measures of central tendency (Lew, 2011). Thus, in the ADHD literature, there has been a movement towards examining IIV as an endophenotype (Vaurio et al., 2009).

Differences in IIV have also been observed in other populations. Across the lifespan, IIV follows a U-shaped pattern, decreasing over adolescence and adulthood, and increasing again in late life (MacDonald et al., 2006). In addition, those with schizophrenia, dementia, and TBI also have greater IIV compared to controls (MacDonald et al., 2006). 
Several studies have already reported greater IIV in PTSD compared to controls. Importantly, Swick et al. (Swick et al., 2013) found that compared to combat controls, veterans with PTSD had greater IIV on a Go/No-Go task, even though the mean RTs between the groups were the same. Greater IIV was also associated with greater PTSD symptoms. Veltmeyer et al. (Veltmeyer, 2005) also reported that PTSD subjects had greater IIV on an auditory oddball task as well as on a visual target detection task (Veltmeyer and Clark, 2009).

IIV can affect other variables besides simple RT. For example, Neylan et al. (Neylan et al., 2003) showed that while there were no group differences in P3 amplitude and latency on an ERP oddball task, the PTSD group had significantly greater P3 variability than controls. Moreover, three studies have examined IIV on the dot-probe task, finding that those with PTSD had greater variability in their attentional bias towards threat, which may explain conflicting findings in past studies. Iacoviello et al. (Iacoviello et al., 2014), was the first group to show that within a single session, attention bias can fluctuate between states of vigilance and states of avoidance. In comparing a PTSD group to TEC and NTC, they reported that those with PTSD had greater attention bias variability. They also found in a prospective study of soldiers that before deployment there were no differences in attention bias variability, but during deployment, those reporting greater levels of acute stress had greater attention bias variability. Naim et al. (Naim et al., 2015) further implicated attention bias variability in seven independent samples of PTSD. They found that those with PTSD had more threat-bias variability on the dot-probe than trauma controls, healthy subjects, those with social anxiety, and undergraduate students with high trait anxiety. Thus, attention variability may be a 
useful marker in determining who will develop PTSD. More research is needed in this area however, as three studies (Barlow-Ogden and Poynter, 2012; Ogden, 2010; Trudeau and Anderson, 1998) have found that differences in IIV were mainly in PTSD groups who also had TBI. Further research is needed to parse out the contribution of PTSD and TBI to IIV.

To address this question, we examined IIV on the ANT in a sample of 51 male Operation Enduring Freedom/Operation Iraqi Freedom veterans (mean age $=32,19$ with mild TBI, 38 taking psychiatric medication) compared to 26 healthy male community controls (mean age $=31$, no psychiatric medications or current comorbidities), controlling for education level as intellectual ability could be related to attentional functioning. We first compared the standard deviation (SD) of RTs across the whole task with education level as a covariate $(1=$ some graduate school or graduate degree, $2=$ some college or college degree, 3 = high school graduate), finding that the PTSD group showed greater SD than controls, $F(1,72)=4.173, p=0.046$.

Next we compared the SD of RT within each trial type (congruent, incongruent, and neutral flanker) after mean-centering for mean RT within each condition type (3 flanker $\mathrm{x} 4$ cue types) with education level as a covariate. .We found that the PTSD group showed greater SD than controls in neutral flanker trials, $F(1,72)=3.809, p=0.055, \mathrm{~d}=$ 0.91 , and marginally greater SD in congruent $(p=0.187, \mathrm{~d}=0.50)$ and incongruent $(p=$ $0.084, \mathrm{~d}=1.00)$ trials; however the effect sizes for all three of these trial types were moderate to large, and the SDs were significant when education was not entered as a covariate. 
Because of our findings that PTSD subjects demonstrated difficulty disengaging their attention from the center cue location (Block et al. under review), we also examined RT SD of trials preceded by center cues, similarly finding that PTSD subjects had greater $\mathrm{SD}$ in neutral flanker trials with a large effect size, $F(1,72)=3.379, p=0.070, \mathrm{~d}=0.61$ $(p=0.019$ without education covariate) compared to controls. We did not find any differences in the above measures between those with and without mild TBI or those on psychiatric medications. The fact that our strongest findings were in neutral flanker trials suggests that consistency in performance might be independent from conflict monitoring.

\section{Neural Correlates of Performance Variability}

There are three hypotheses regarding the neural origins of IIV. According to the first, IIV reflects inefficient cognitive control in the DAN, VAN and FPCN (MacDonald et al., 2006). Indeed, individuals with frontal lobe lesions show greater IIV (Stuss et al., 2003). Bellgrove et al. (Bellgrove et al., 2004) examined the neural correlates of IIV in healthy individuals during a Go/No-Go task, finding that greater IIV correlated with greater inferior parietal, middle frontal and thalamic activity, potentially due to a greater demand on these areas to execute inhibition. Decreased efficiency of these networks has also been reported in the elderly and those with schizophrenia, populations who have greater IIV (MacDonald et al., 2006). Only one ERP study has examined this hypothesis in PTSD, finding that during an oddball task greater IIV was correlated with decreased P3 amplitude and delayed N2 latency in frontoparietal areas related to working memory and attention (Veltmeyer, 2005). While this supports the role of these neural networks in IIV, further research is needed to examine this hypothesis in PTSD. 
According to the second hypothesis, attentional lapses occur when the DMN intrudes upon task-positive networks potentially reflecting mind-wandering (Weissman et al., 2006). Supporting the idea that DMN intrusion impairs attentional capacity, studies in healthy populations have found that decreased anti-correlation between task-negative and task-positive networks predicts poorer cognitive performance in Stroop (Harrison et al., 2005), flanker (Clare Kelly et al., 2008) and working memory tasks (Hampson and Driesen, 2006; Zou et al., 2013). Additionally, DMN intrusion during externally focused tasks results in lapses of attention (Sonuga-Barke and Castellanos, 2007; Weissman et al., 2006). Interestingly, ADHD is also associated with decreased DMN segregation (Sripada et al., 2014). In PTSD, numerous studies have found that the DMN fails to deactivate (Pannu Hayes et al., 2009), is less segregated (Chen and Etkin, 2013; Rabellino et al., 2015) and is hyper-perfused (Raji et al., 2015) during cognitive tasks, while at rest, there is similarly less segregation of the network (Bluhm et al., 2009; R. K. Sripada et al., 2012; Wu et al., 2011). Thus while the DMN intrusion is the predominant theory in the ADHD literature, no PTSD studies have examined the correlation of IIV specifically with fMRI activation or connectivity.

A third possibility is that IIV in PTSD may reflect SN intrusions upon other ICNs (Swick et al., 2013), potentially leading to hypervigilance or intrusive thoughts. Support for this hypothesis stems from the evidence of greater SN cross network connectivity in PTSD (Bluhm et al., 2009; Rabellino et al., 2015; R. K. Sripada et al., 2012) and the abundance of altered SN activation during cognitive tasks, discussed earlier. Interestingly, ADHD is also associated with SN alterations (Sripada et al., 2014). The relationship between IIV and SN functioning, however, remains to be tested in PTSD. 
In sum, IIV may result from alterations of multiple task-positive and task-negative neural networks. As IIV has been shown to be a strong correlate of attentional impairments, it may be useful to examine the neural correlates of IIV as a future step in PTSD research.

\section{Treatment Implications}

Understanding attentional processes in PTSD may one day lead to novel treatments and better understanding of treatment mechanisms. This has already gained interest in the attention bias literature, which has investigated whether attention bias modification (ABM) training can ameliorate symptoms either as a stand-alone treatment or as an adjunct to psychotherapy (Bar - Haim, 2010). There has been some success of this intervention in the laboratory for other psychiatric populations (Beard et al., 2012), but it has not been successful in non-laboratory settings, such as on a smart-phone (Enock et al., 2014). Only two studies have examined the effects of attention training in PTSD. Schoorl et al. (Schoorl et al., 2013) reported that ABM training produced similar effect sizes to those observed with placebo drugs on PTSD symptoms, and that neither training away from threat nor control training affected attentional biases. Kuckertz et al. (Kuckertz et al., 2014), on the other hand, found that ABM away from threat was a more affective adjunct to individual psychotherapy in reducing PTSD symptoms than a control attention training. This suggests modification of attention biases might be possible, however, more research is needed regarding computerized attention training in this population.

Both attentional bias and IIV may be useful markers for treatment progress. El Khoury et al. (Khoury-Malhame and Lanteaume, 2011), reported that Eye Movement 
Desensitization and Reprocessing treatment reduced the difference in attentional biases between patients and healthy controls on the emotional-Stroop and DOT test. BaduraBrack et al. (Badura-Brack and Naim, 2015) reported that attention training equally towards and away from threat using a dot-probe led to a significant decrease in PTSD symptoms, as well as reduced attention bias variability in two populations of veterans. Furthermore, this reduction in variability was partially mediated by symptom improvement. ABM towards threat however, did not significantly change symptoms or IIV. These studies suggest that general attentional control with an emphasis on consistency may be a key towards better PTSD treatment.

Further insights regarding treatment mechanisms have come from neuroimaging scans before and after treatment. Falconer et al. (Falconer and Allen, 2013) found that greater SN, DAN, VAN and DMN activity on a Go/No-Go task predicted poorer outcomes after eight weeks of cognitive-behavioral therapy (CBT). In concert, Thomaes et al. (Thomaes and Dorrepaal, 2012) found that after CBT, symptom improvement was associated with decreased AACC and AI activity in the emotional-Stroop. The authors concluded that treatment resulted in improved selective attention, lower emotional arousal, and greater cognitive control over PTSD symptoms.

Combining multiple methodologies will most likely lead to increased understanding of PTSD. In an eloquent study, Falconer et al. (Falconer and Felmingham, 2008) used a battery of neuropsychological and physiological measures in PTSD and NTC, and then further built a classification model to determine which measures would most accurately distinguish the two groups. They found that a combination of factors including resting-state physiological arousal, Stroop interference, auditory oddball P3 
amplitude, cognitive flexibility in the TMT, RT on a working memory task, and accuracy in a visuospatial maze task, was able to correctly classify $81 \%$ of the PTSD group. The authors concluded that these measures might be useful in assessment of PTSD subtypes as well as predicting and evaluating treatment response.

The hope for many providers, however, is not only to predict, but to enhance treatment response. Using the methodologies outlined above, we may gain a better understanding of the specific neural circuitry implicated in PTSD and use treatments that target these circuits. Direct alteration of brain activity using technologies such as deep brain stimulation and transcranial magnetic stimulation have already been tested on other psychiatric populations including Major Depression and Obsessive Compulsive Disorder with promising success (Ressler and Mayberg, 2007). At home or in the office, patients could also learn to modify affected neural circuits by practicing tasks that rely on these same circuits (Vinogradov et al., 2012). Selecting cognitive tasks that are specific to particular neural circuits could be tested as a future treatment approach.

\section{Conclusion}

PTSD is associated with a number of alternations in attention at the behavioral and neural level. Although many findings are mixed and the studies so far were unable to parse out mechanisms underlying these alterations, they do suggest that attentional processes such as hypervigilance, disengagement, response inhibition and conflict monitoring may be implicated in PTSD development. Research focusing on intraindividual variability in addition to measures of central tendency may help clarify these mixed findings. Neuroimaging work is also likely to be useful in understanding attentional processes in PTSD, as our understanding of the neuroanatomy of attention is 
rapidly progressing. Neuroimaging research most consistently implicates DMN and SN alterations in PTSD, with desegregation of these networks possibly reflecting attentional impairments and symptomatology. It also suggests that the VAN, DAN and FPCN may be affected in PTSD, however further research is needed to study the functioning of these networks in PTSD during attention tasks which isolate attention components. Attentional impairments might be both a risk factor for and consequence of PTSD. Inefficient attentional networks may make one more vulnerable to develop PTSD, but PTSD may also further change attention functioning. Furthermore, the heterogeneity of traumatic experiences (motor vehicle accident, sexual abuse, combat, etc.) that lead to PTSD, as well as the duration of the traumatic event (single event or prolonged exposure) are additional variables that may interact with attentional functioning. Longitudinal studies on attentional processes in PTSD are thus warranted. Future research integrating behavioral and neural measures of attention will be most useful in understanding the pathophysiology of PTSD. 


\section{Acknowledgements and Financial Disclosures}

We thank Anthony King, Ph.D. for contribution of his OEF/OIF dataset that was used for the reaction time variability analyses. We thank Daniel Kessler for his assistance with statistical analysis.

This project was supported in by the Department of Defense [Grant W81XWH082020a8]; and the Mind and Life Institute [Varela Award].

Stefanie R. Block, MS is supported by the University of Michigan Psychology

Department and the VA Ann Arbor Healthcare System, and has no potential conflict of interest.

Israel Liberzon, MD has been supported by the Department of Defense and declares no conflict of interest. 


\section{References}

Adler, L. a, Kunz, M., Chua, H.C., Rotrosen, J., Resnick, S.G., 2004. Attentiondeficit/hyperactivity disorder in adult patients with posttraumatic stress disorder (PTSD): is ADHD a vulnerability factor? J Atten.Disord 8, 11-16. doi:10.1177/108705470400800102

Adólfsdóttir, S., Sørensen, L., Lundervold, A.J., 2008. The attention network test: a characteristic pattern of deficits in children with ADHD. Behav. Brain Funct. 4, 9. doi:10.1186/1744-9081-4-9

American Psychiatric Association, 2013. DSM-V, American Journal of Psychiatry. doi:10.1176/appi.books.9780890425596.744053

Armengol, C., 2003. Differential Performance of Post-traumatic stress disorder (PTSD), Attention deficit hyperactivity disorder (ADHD), and a Non-Clinical Control Group on Tests of. Rev. española ....

Aupperle, R.L., Melrose, A.J., Stein, M.B., Paulus, M.P., 2012. Executive function and PTSD: Disengaging from trauma. Neuropharmacology 62, 686-694.

doi:10.1016/j.neuropharm.2011.02.008

Awh, E., Vogel, E., Oh, S., 2006. Interactions between attention and working memory. Neuroscience.

Badura-Brack, A., Naim, R., 2015. Effect of attention training on attention bias variability and PTSD symptoms: randomized controlled trials in Israeli and US combat veterans. Am. J. ....

Bardeen, J., Orcutt, H., 2011. Attentional control as a moderator of the relationship between posttraumatic stress symptoms and attentional threat bias. J. Anxiety Disord.

Bar- Haim, Y., 2010. Research review: attention bias modification (ABM): a novel treatment for anxiety disorders. J. Child Psychol. Psychiatry.

Barlow-Ogden, K., Poynter, W., 2012. Mild traumatic brain injury and posttraumatic stress disorder: Investigation of visual attention in Operation Iraqi

Freedom/Operation Enduring Freedom veterans. J. Rehabil. ....

Beard, C., Sawyer, A.T., Hofmann, S.G., 2012. Efficacy of Attention Bias Modification Using Threat and Appetitive Stimuli: A Meta-Analytic Review. Behav. Ther. 43, 724-740. doi:10.1016/j.beth.2012.01.002

Beck, J., Freeman, J., 2001. Specificity of Stroop interference in patients with pain and PTSD. J. Abnorm. ....

Beevers, C., Lee, H., 2014. Association of predeployment gaze bias for emotion stimuli with later symptoms of PTSD and depression in soldiers deployed in Iraq. Am. J.

Bellgrove, M. a., Hester, R., Garavan, H., 2004. The functional neuroanatomical correlates of response variability: Evidence from a response inhibition task. Neuropsychologia 42, 1910-1916. doi:10.1016/j.neuropsychologia.2004.05.007

Bellis, M. De, Woolley, D., Hooper, S., 2013. Neuropsychological findings in pediatric 
maltreatment: relationship of PTSD, dissociative symptoms, and abuse/neglect indices to neurocognitive outcomes. Child Maltreat.

Bennett, T., Raymond, M., Malia, K., Bewick, K., \& Linton, B., 1998. Rehabilitation of attention and concentration deficits following brain injury. J. Cogn. Rehabil. 8-13.

Beran, M., Washburn, D., Kleinman, S., 2003. Attention Network Task (ANT) performance by children and rhesus monkeys., in: 44th Annual Meeting of the Psychonomic Society, Vancouver, Canada.

BERG, E.A., 1948. A simple objective technique for measuring flexibility in thinking. J. Gen. Psychol. 39, 15-22. doi:10.1080/00221309.1948.9918159

Blair, K., Vythilingam, M., 2013. Cognitive control of attention is differentially affected in trauma-exposed individuals with and without post-traumatic stress disorder. Psychol. ....

Bluhm, R.L., Williamson, P.C., Osuch, E.A., Frewen, P.A., Stevens, T.K., Boksman, K., Neufeld, R.W.J., Théberge, J., Lanius, R.A., 2009. Alterations in default network connectivity in posttraumatic stress disorder related to early-life trauma. J. Psychiatry Neurosci. 34, 187-194.

Brandes, D., Ben-Schachar, G., Gilboa, A., Bonne, O., Freedman, S., Shalev, A.Y., 2002a. PTSD symptoms and cognitive performance in recent trauma survivors. Psychiatry Res. 110, 231-238. doi:10.1016/S0165-1781(02)00125-7

Brandes, D., Ben-Schachar, G., Gilboa, A., Bonne, O., Freedman, S., Shalev, A.Y., 2002b. PTSD symptoms and cognitive performance in recent trauma survivors. Psychiatry Res. 110, 231-238. doi:10.1016/S0165-1781(02)00125-7

Bremner, J., Vermetten, E., Vythilingam, M., 2004. Neural correlates of the classic color and emotional stroop in women with abuse-related posttraumatic stress disorder. Biol. ....

Brock, S., Clinton, A., 2007. Diagnosis of attention-deficit/hyperactivity disorder (AD/HD) in childhood: A review of the literature. Calif. Sch. Psychol.

Bryant, R. a, Felmingham, K.L., Kemp, a H., Barton, M., Peduto, a S., Rennie, C., Gordon, E., Williams, L.M., 2005. Neural networks of information processing in posttraumatic stress disorder: a functional magnetic resonance imaging study. Biol Psychiatry 58, 111-118. doi:10.1016/j.biopsych.2005.03.021

Bryant, R., Harvey, A., 1997. Attentional bias in posttraumatic stress disorder. J. Trauma. Stress.

Buckner, R.L., Vincent, J.L., 2007. Unrest at rest: default activity and spontaneous network correlations. Neuroimage 37, 1091-6; discussion 1097-9. doi:10.1016/j.neuroimage.2007.01.010

Burriss, L., Ayers, E., Ginsberg, J., Powell, D. a, 2008. Learning and memory impairment in PTSD: relationship to depression. Depress. Anxiety 25, 149-57. doi:10.1002/da.20291

Casada, J.H., Roache, J.D., 2005. Behavioral Inhibition and Activation in Posttraumatic Stress Disorder. J. Nerv. Ment. Dis. 193, 102-109. 
doi:10.1097/01.nmd.0000152809.20938.37

Chen, A.C., Etkin, A., 2013. Hippocampal network connectivity and activation differentiates post-traumatic stress disorder from generalized anxiety disorder. Neuropsychopharmacology 38, 1889-98. doi:10.1038/npp.2013.122

Clare Kelly, a. M., Uddin, L.Q., Biswal, B.B., Castellanos, F.X., Milham, M.P., 2008. Competition between functional brain networks mediates behavioral variability. Neuroimage 39, 527-537. doi:10.1016/j.neuroimage.2007.08.008

Coghill, D.R., Seth, S., Matthews, K., 2013. A comprehensive assessment of memory, delay aversion, timing, inhibition, decision making and variability in attention deficit hyperactivity disorder: advancing beyond the three-pathway models. Psychol. Med. 1-13. doi:10.1017/S0033291713002547

Connor, K.M., Sutherland, S.M., Tupler, L.A., Malik, M.L., Davidson, J.R., 1999. Fluoxetine in post-traumatic stress disorder. Randomised, double-blind study. Br. J. Psychiatry 175, 17-22.

Constans, J., McCloskey, M., 2004. Suppression of attentional bias in PTSD. J. Abnorm.

Corbetta, M., Shulman, G.L., 2002. Control of goal-directed and stimulus-driven attention in the brain. Nat. Rev. Neurosci. 3, 201-215. doi:10.1038/nrn755

Crowell, T. a, Kieffer, K.M., Siders, C. a, Vanderploeg, R.D., 2002. Neuropsychological findings in combat-related posttraumatic stress disorder. Clin. Neuropsychol. 16, 310-21. doi:10.1076/clin.16.3.310.13851

Dalgleish, T., Moradi, A., 2001. An experimental investigation of hypervigilance for threat in children and adolescents with post-traumatic stress disorder. Psychol. ....

Daniels, J.K., Bluhm, R.L., Lanius, R. a., 2013. Intrinsic network abnormalities in posttraumatic stress disorder: Research directions for the next decade. Psychol. Trauma Theory, Res. Pract. Policy 5, 142-148. doi:10.1037/a0026946

Daud, A., Rydelius, P., 2009. Comorbidity/overlapping between ADHD and PTSD in relation to IQ among children of traumatized/non-traumatized parents. J. Atten. Disord.

Disorder, C. on the A. of O.E. in the T. of P.S., Populations, B. on the H. of S., Medicine, I. of, 2014. Access to Care.

Elsesser, K., Sartory, G., Tackenberg, A., 2004. Attention, heart rate, and startle response during exposure to trauma-relevant pictures: a comparison of recent trauma victims and patients with posttraumatic stress. J. Abnorm. ....

Enock, P.M., Hofmann, S.G., McNally, R.J., 2014. Attention Bias Modification Training Via Smartphone to Reduce Social Anxiety: A Randomized, Controlled MultiSession Experiment. Cognit. Ther. Res. 38, 200-216. doi:10.1007/s10608-0149606-z

Eren- Koçak, E., Kılıç, C., 2009. Memory and prefrontal functions in earthquake survivors: differences between current and past post- traumatic stress disorder patients. Acta Psychiatr. .... 
Eriksen, B., Eriksen, C., 1974. Effects of noise letters upon the identification of a target letter in a nonsearch task. Percept. Psychophys.

Falconer, E., Allen, A., 2013. Inhibitory neural activity predicts response to cognitivebehavioral therapy for posttraumatic stress disorder. J. Clin. ....

Falconer, E., Bryant, R., 2008. The neural networks of inhibitory control in posttraumatic stress disorder. J. psychiatry ....

Falconer, E., Bryant, R., Felmingham, K.L., Kemp, A.H., Gordon, E., Peduto, A., Olivieri, G., Medrad, A., Williams, L.M., 2008. The neural networks of inhibitory control in posttraumatic stress disorder 33, 413-422.

Falconer, E., Felmingham, K., 2008. Developing an integrated brain, behavior and biological response profile in posttraumatic stress disorder (PTSD). J. Integr. ....

Fan, J., McCandliss, B.D., Fossella, J., Flombaum, J.I., Posner, M.I., 2005. The activation of attentional networks. Neuroimage 26, 471-479. doi:10.1016/j.neuroimage.2005.02.004

Fan, J., McCandliss, B.D., Sommer, T., Raz, A., Posner, M.I., 2002. Testing the efficiency and independence of attentional networks. J. Cogn. Neurosci. 14, 340347.

Fan, J., Posner, M., 2004. Human attentional networks. Psychiatr. Prax.

Fani, N., Bradley-Davino, B., 2011. Attention bias in adult survivors of childhood maltreatment with and without posttraumatic stress disorder. Cogn. Ther. ....

Fani, N., Tone, E., Phifer, J., 2012. Attention bias toward threat is associated with exaggerated fear expression and impaired extinction in PTSD. Psychol. ....

Felmingham, K., Rennie, C., 2011. Eye tracking and physiological reactivity to threatening stimuli in posttraumatic stress disorder. J. Anxiety Disord.

Felmingham, K.L., Williams, L.M., Kemp, A.H., Rennie, C., Gordon, E., Bryant, R.A., 2009. Anterior cingulate activity to salient stimuli is modulated by autonomic arousal in Posttraumatic Stress Disorder. Psychiatry Res. - Neuroimaging 173, 5962. doi:10.1016/j.pscychresns.2008.12.005

Fleurkens, P., Rinck, M., Minnen, A. van, 2011. Specificity and generalization of attentional bias in sexual trauma victims suffering from posttraumatic stress disorder. J. Anxiety Disord.

Foa, E., Feske, U., Murdock, T., 1991. Processing of threat-related information in rape victims. J. Abnorm. ....

Frewen, P.A., Lanius, R.A., 2006. Toward a Psychobiology of Posttraumatic SelfDysregulation. Ann. N. Y. Acad. Sci. 1071, 110-124. doi:10.1196/annals.1364.010

Gil, T., Calev, A., Greenberg, D., Kugelmass, S., 1990. Cognitive functioning in posttraumatic stress disorder. J. Trauma. Stress 3, 29-45. doi:10.1007/BF00975134

Gilbertson, M., Paulus, L., 2006. Neurocognitive function in monozygotic twins discordant for combat exposure: relationship to posttraumatic stress disorder. J. Abnorm. .... 
Golier, J., Yehuda, R., Cornblatf, B., Harvey, P., 1997. Sustained Attention in Combatrelated Posttraumatic Stress Disorder 32, 52-61.

Gooding, D., Braun, J., Studer, J., 2006. Attentional network task performance in patients with schizophrenia-spectrum disorders: Evidence of a specific deficit. Schizophr. Res.

Green, B.L., Krupnick, J.L., Stockton, P., Goodman, L., Corcoran, C., Petty, R., 2005. Effects of adolescent trauma exposure on risky behavior in college women. Psychiatry 68, 363-378. doi:10.1521/psyc.2005.68.4.363

Greenberg, L., Kindschi, C., 1994. Test of Variables of Attention continuous performance test. TOVA ....

Greene, D.J., Barnea, A., Herzberg, K., Rassis, A., Neta, M., Raz, A., Zaidel, E., 2008. Measuring attention in the hemispheres: the lateralized attention network test (LANT). Brain Cogn. 66, 21-31. doi:10.1016/j.bandc.2007.05.003

Gurvits, T., 2000. Neurologic soft signs in chronic posttraumatic stress disorder. ... Psychiatry.

Hahn, B., Ross, T.J., Stein, E. a., 2006. Neuroanatomical dissociation between bottom-up and top-down processes of visuospatial selective attention. Neuroimage 32, 842853. doi:10.1016/j.neuroimage.2006.04.177

Hampson, M., Driesen, N., 2006. Brain connectivity related to working memory performance. J. ....

Harrison, B., Shaw, M., Yücel, M., Purcell, R., 2005. Functional connectivity during Stroop task performance. Neuroimage.

Harvey, A., Bryant, R., Rapee, R., 1996. Preconscious processing of threat in posttraumatic stress disorder. Cognit. Ther. Res.

Hayes, J., LaBar, K., Petty, C., 2009. Alterations in the neural circuitry for emotion and attention associated with posttraumatic stress symptomatology. Psychiatry Res. ....

Hembree, E. a., Foa, E.B., Dorfan, N.M., Street, G.P., Kowalski, J., Tu, X., 2003. Do Patients Drop Out Prematurely from Exposure Therapy for PTSD? J. Trauma. Stress 16, 555-562. doi:10.1023/B:JOTS.0000004078.93012.7d

Horner, M.D., Horner, M.D., Hamner, M.B., 2002. Horner MD , Hamner MB . Neurocognitive functioning in posttraumatic stress disorder Neurocognitive Functioning in Posttraumatic Stress Disorder. doi:10.1023/A

Iacoviello, B.M., Wu, G., Abend, R., Murrough, J.W., Feder, A., Fruchter, E., Levinstein, Y., Wald, I., Bailey, C.R., Pine, D.S., Neumeister, A., Bar-Haim, Y., Charney, D.S., 2014. Attention Bias Variability and Symptoms of Posttraumatic Stress Disorder. J. Trauma. Stress 27, 232-239. doi:10.1002/jts.21899

Ipser, J., Seedat, S., Stein, D.J., 2006. Pharmacotherapy for post-traumatic stress disorder - a systematic review and meta-analysis. S. Afr. Med. J. 96, 1088-96.

Jakupcak, M., Conybeare, D., Phelps, L., Hunt, S., Holmes, H.A., Felker, B., Klevens, M., McFall, M.E., 2007. Anger, hostility, and aggression among Iraq and Afghanistan war veterans reporting PTSD and subthreshold PTSD. J. Trauma. Stress 
20, 945-954. doi:10.1002/jts.20258

James, W., 1890. The principles of psychology (Vols. 1 \& 2). New York Holt 118, 688. doi:10.1037/10538-000

Jenkins, M., Langlais, P., 2000. Attentional dysfunction associated with posttraumatic stress disorder among rape survivors. Clin. ....

Jenkins, M.A., Langlais, P.J., Delis, D., Cohen, R.A., Jenkins, M.A., Langlais, P.J., Delis, D., Cohen, R.A., 2010. The Clinical Neuropsychologist Attentional Dysfunction Associated with Posttraumatic Stress Disorder Among Rape Survivors Attentional Dysfunction Associated with Posttraumatic Stress Disorder Among Rape Survivors *. doi:10.1076/1385-4046(200002)14

Jennings, J.M., Dagenbach, D., Engle, C.M., Funke, L.J., 2007. Age-related changes and the attention network task: an examination of alerting, orienting, and executive function. Neuropsychol. Dev. Cogn. B. Aging. Neuropsychol. Cogn. 14, 353-69. doi:10.1080/13825580600788837

Jha, A.P., Krompinger, J., Baime, M.J., 2007. Mindfulness training modifies subsystems of attention. Cogn. Affect. Behav. Neurosci. 7, 109-19.

John Hart, J.. M.D., Timothy Kimbrell, M.D., Peter Fauver, M.A., Barbara J. Cherry, P.D., Jeffery Pitcock, M.A., Leroy Q. Booe, M.D., Gail Tillman, P.D., Thomas W. Freeman, M.D., 2008. Cognitive Dysfunctions Associated With PTSD: Evidence from World War II Prisoners of War. J. Neuropsychiatry Clin. Neurosci.

Johnsen, G.E., Asbjørnsen, A.E., 2008. Consistent impaired verbal memory in PTSD: a meta-analysis. J. Affect. Disord. 111, 74-82. doi:10.1016/j.jad.2008.02.007

Kanagaratnam, P., Asbjørnsen, A.E., 2007. Executive deficits in chronic PTSD related to political violence. J. Anxiety Disord. 21, 510-25. doi:10.1016/j.janxdis.2006.06.008

Khoury-Malhame, M. El, Lanteaume, L., 2011. Attentional bias in post-traumatic stress disorder diminishes after symptom amelioration. Behav. Res. ....

Khoury-Malhame, M. El, Reynaud, E., 2011. Amygdala activity correlates with attentional bias in PTSD. Neuropsychologia.

Kimble, M., Fleming, K., Bandy, C., 2010. Eye tracking and visual attention to threating stimuli in veterans of the Iraq war. J. Anxiety ....

Kimble, M., Frueh, B., Marks, L., 2009. Does the modified Stroop effect exist in PTSD? Evidence from dissertation abstracts and the peer reviewed literature. J. Anxiety Disord.

Kimbrel, N.A., Johnson, M.E., Clancy, C., Hertzberg, M., Collie, C., Van Voorhees, E.E., Dennis, M.F., Calhoun, P.S., Beckham, J.C., 2014. Deliberate self-harm and suicidal ideation among male Iraq/Afghanistan-era veterans seeking treatment for PTSD. J. Trauma. Stress 27, 474-477. doi:10.1002/jts.21932

Kivling-Bodén, G., Sundbom, E., 2003. Cognitive abilities related to post-traumatic symptoms among refugees from the former Yugoslavia in psychiatric treatment. Nord. J. Psychiatry 57, 191-198. doi:10.1080/08039480310001346

Koenen, K.C., Driver, K.L., Oscar-Berman, M., Wolfe, J., Folsom, S., Huang, M.T., 
Schlesinger, L., 2001a. Measures of prefrontal system dysfunction in posttraumatic stress disorder. Brain Cogn. 45, 64-78. doi:10.1006/brcg.2000.1256

Koenen, K.C., Driver, K.L., Oscar-Berman, M., Wolfe, J., Folsom, S., Huang, M.T., Schlesinger, L., 2001b. Measures of prefrontal system dysfunction in posttraumatic stress disorder. Brain Cogn. 45, 64-78. doi:10.1006/brcg.2000.1256

Koso, M., Hansen, S., 2006a. Executive function and memory in posttraumatic stress disorder: a study of Bosnian war veterans. Eur. Psychiatry 21, 167-73. doi:10.1016/j.eurpsy.2005.06.004

Koso, M., Hansen, S., 2006b. Executive function and memory in posttraumatic stress disorder: a study of Bosnian war veterans. Eur. Psychiatry 21, 167-73. doi:10.1016/j.eurpsy.2005.06.004

Koso, M., Sarač-Hadžihalilović, A., Hansen, S., 2012. Neuropsychological performance, psychiatric symptoms, and everyday cognitive failures in Bosnian ex-servicemen with posttraumatic stress disorder. Rev. Psychol.

Krikorian, R., Bartok, J., Gay, N., Anonymous, 1994. Tower-Of-London Procedure - a Standard Method and Developmental-Data. J. Clin. Exp. Neuropsychol. 16, 840850.

Kuckertz, J., Amir, N., Boffa, J., 2014. The effectiveness of an attention bias modification program as an adjunctive treatment for post-traumatic stress disorder. Behav. Res. ....

Kucyi, a., Hodaie, M., Davis, K.D., 2012. Lateralization in intrinsic functional connectivity of the temporoparietal junction with salience- and attention-related brain networks. J. Neurophysiol. 108, 3382-92. doi:10.1152/jn.00674.2012

LaGarde, G., Doyon, J., Brunet, A., 2010. Memory and executive dysfunctions associated with acute posttraumatic stress disorder. Psychiatry Res.

Lagarde, G., Doyon, J., Brunet, A., 2010. Memory and executive dysfunctions associated with acute posttraumatic stress disorder. Psychiatry Res. 177, 144-9. doi:10.1016/j.psychres.2009.02.002

Lapham, S.C., C'de Baca, J., McMillan, G.P., Lapidus, J., 2006. Psychiatric disorders in a sample of repeat impaired-driving offenders. J. Stud. Alcohol 67, 707-713.

Leskin, L.P., White, P.M., 2007. Attentional networks reveal executive function deficits in posttraumatic stress disorder. Neuropsychology 21, 275-284. doi:10.1037/08944105.21.3.275

Lew, H., 2011. Prevalence and characteristics of driving difficulties in Operation Iraqi Freedom/Operation Enduring Freedom combat returnees. J. Rehabil. ....

Lindauer, R., Olff, M., Meijel, E. van, 2006. Cortisol, learning, memory, and attention in relation to smaller hippocampal volume in police officers with posttraumatic stress disorder. Biol. ....

Luxenberg, T., Spinazzola, J., Kolk, B. Van der, 2001. Complex trauma and disorders of extreme stress (DESNOS) diagnosis, part one: Assessment. Dir. Psychiatry.

MacDonald, S.W.S., Nyberg, L., Bäckman, L., 2006. Intra-individual variability in 
behavior: links to brain structure, neurotransmission and neuronal activity. Trends Neurosci. doi:10.1016/j.tins.2006.06.011

MacLeod, C., Mathews, A., Tata, P., 1986. Attentional bias in emotional disorders. J. Abnorm. Psychol. 95, 15-20. doi:10.1037/0021-843X.95.1.15

Macleod, J.W., Lawrence, M.A., McConnell, M.M., Eskes, G.A., Klein, R.M., Shore, D.I., 2010. Appraising the ANT: Psychometric and theoretical considerations of the Attention Network Test. Neuropsychology 24, 637-651. doi:10.1037/a0019803

Markett, S., Reuter, M., Montag, C., Voigt, G., Lachmann, B., Rudorf, S., Elger, C.E., Weber, B., 2014. Assessing the function of the fronto-parietal attention network: Insights from resting-state fMRI and the attentional network test. Hum. Brain Mapp. 35, 1700-1709. doi:10.1002/hbm.22285

McFarlane, A.C., Weber, D.L., Clark, C.R., 1993. Abnormal stimulus processing in posttraumatic stress disorder. Biol. Psychiatry 34, 311-320. doi:10.1016/00063223(93)90088-U

McNally, R., Kaspi, S., 1990. Selective processing of threat cues in posttraumatic stress disorder. J. Abnorm. ....

Menon, V., Uddin, L.Q., 2010. Saliency, switching, attention and control: a network model of insula function. Brain Struct. Funct. 214, 1-13. doi:10.1007/s00429-0100262-0

Mogg, K., Bradley, B.P., 1998. A cognitive-motivational analysis of anxiety. Behav. Res. Ther. doi:10.1016/S0005-7967(98)00063-1

Monastra, V., 2008. Unlocking the potential of patients with ADHD: A model for clinical practice.

Moradi, A.R., Neshat-Doost, H.T., Teghavi, R., Yule, W., Dalgleish, T., 1999. Performance of children of adults with PTSD on the stroop color-naming task: a preliminary study. J. Trauma. Stress 12, 663-71. doi:10.1023/A:1024721218869

Morey, R., Petty, C., Cooper, D., 2008. Neural systems for executive and emotional processing are modulated by symptoms of posttraumatic stress disorder in Iraq War veterans. Psychiatry Res. ....

Naim, R., Abend, R., Wald, I., 2015. Threat-Related Attention Bias Variability and Posttraumatic Stress. Am. J. ....

Netto, L.R., Pereira, J.L., Nogueira, J.F., Cavalcanti-Ribeiro, P., Santana, R.C., Teles, C.A., Koenen, K.C., Quarantini, L.C., 2016. Impulsivity is relevant for trauma exposure and PTSD symptoms in a non-clinical population. Psychiatry Res. 239, 204-211. doi:10.1016/j.psychres.2016.03.027

Neylan, T.C., Jasiukaitis, P.A., Lenoci, M., Scott, J.C., Metzler, T.J., Weiss, D.S., Schoenfeld, F.B., Marmar, C.R., 2003. Temporal instability of auditory and visual event-related potentials in posttraumatic stress disorder. Biol. Psychiatry 53, 21625.

Neylan, T.-C., Lenoci, M., Rothlind, J., Metzler, T.-J., Schuff, N., Du, A.-T.T., Franklin, K.-W., Weiss, D.-S., Weiner, M.-W., Marmar, C.-R., 2004. Attention, learning, and 
memory in posttraumatic stress disorder. J Trauma Stress 17, 41-46.

doi:10.1023/B:JOTS.0000014675.75686.ee

Ochsner, K.N., Gross, J.J., 2005. The cognitive control of emotion. Trends Cogn. Sci.

Ogden, K., 2010. Traumatic brain injury and posttraumatic stress disorder: a quantitative investigation of vision and attention.

Pacheco-Unguetti, A.P., Acosta, A., Marqués, E., Lupiáñez, J., 2011. Alterations of the attentional networks in patients with anxiety disorders. J. Anxiety Disord. 25, 888895. doi:10.1016/j.janxdis.2011.04.010

Pannu Hayes, J., LaBar, K.S., Petty, C.M., McCarthy, G., Morey, R. a., 2009. Alterations in the neural circuitry for emotion and attention associated with posttraumatic stress symptomatology. Psychiatry Res. - Neuroimaging 172, 7-15. doi:10.1016/j.pscychresns.2008.05.005

Parslow, R.A., Jorm, A.F., 2007. Pretrauma and Posttrauma Neurocognitive Functioning and PTSD Symptoms in a Community Sample of Young Adults. Am J Psychiatry 164, 509-515. doi:10.1176/appi.ajp.164.3.509

Patros, C.H.G., Matt Alderson, R., Kasper, L.J., Tarle, S.J., Lea, S.E., Hudec, K.L., 2015. Choice-impulsivity in children and adolescents with attention-deficit/hyperactivity disorder (ADHD): A meta-analytic review. Clin. Psychol. Rev. doi:10.1016/j.cpr.2015.11.001

Patterson, K., Plaut, D.C., 2009. "Shallow Draughts Intoxicate the Brain": Lessons from Cognitive Science for Cognitive Neuropsychology. Top. Cogn. Sci. 1, 39-58. doi:10.1111/j.1756-8765.2008.01012.x

Paunovic, N., Lundh, L., Öst, L., 2002. Attentional and memory bias for emotional information in crime victims with acute posttraumatic stress disorder (PTSD). J. Anxiety Disord.

Perry, R.J., Hodges, J.R., 1999. Attention and executive deficits in Alzheimer's disease. A critical review. Brain. doi:10.1093/brain/122.3.383

Petersen, Posner, 2012. The attention system of the human brain: 20 years after. Annu. Rev. Neurosci. 35, 73-89. doi:10.1146/annurev-neuro-062111-150525

Phaf, R.H., Kan, K.J., 2007. The automaticity of emotional Stroop: A meta-analysis. J. Behav. Ther. Exp. Psychiatry 38, 184-199. doi:10.1016/j.jbtep.2006.10.008

Pine, D., Mogg, K., 2005. Attention bias to threat in maltreated children: Implications for vulnerability to stress-related psychopathology. Am. J. ....

Pineles, S., Shipherd, J., 2009. Attentional biases in PTSD: More evidence for interference. Behav. Res. ....

Pineles, S., Shipherd, J., Welch, L., Yovel, I., 2007. The role of attentional biases in PTSD: Is it interference or facilitation? Behav. Res. ....

Polak, a R., Witteveen, A.B., Reitsma, J.B., Olff, M., 2012a. The role of executive function in posttraumatic stress disorder: a systematic review. J. Affect. Disord. 141, 11-21. doi:10.1016/j.jad.2012.01.001

Polak, a R., Witteveen, A.B., Reitsma, J.B., Olff, M., 2012b. The role of executive 
function in posttraumatic stress disorder: a systematic review. J. Affect. Disord. 141, 11-21. doi:10.1016/j.jad.2012.01.001

Posner, M.I., 1980. Orienting of attention. Q. J. Exp. Psychol. doi:10.1080/00335558008248231

Posner, M.I., Petersen, S.E., 1990. The attention system of the human brain. Annu. Rev. Neurosci. 13, 25-42. doi:10.1146/annurev.ne.13.030190.000325

Posttraumatic Stress Disorder (PTSD) Alliance, \& U.S. of A., 2000. Posttraumatic Stress Disorder: A Guide for the Frontline [WWW Document]. Posttraumatic Stress Disord. Alliance. URL https://www-ncjrsgov.proxy.lib.umich.edu/App/Publications/abstract.aspx?ID=190596 (accessed 10.17.15).

Power, J.D., Cohen, A.L., Nelson, S.M., Wig, G.S., Barnes, K.A., Church, J.A., Vogel, A.C., Laumann, T.O., Miezin, F.M., Schlaggar, B.L., Petersen, S.E., 2011. Functional network organization of the human brain. Neuron 72, 665-78. doi:10.1016/j.neuron.2011.09.006

Powers, M.B., Halpern, J.M., Ferenschak, M.P., Gillihan, S.J., Foa, E.B., 2010. A metaanalytic review of prolonged exposure for posttraumatic stress disorder. Clin. Psychol. Rev. 30, 635-41. doi:10.1016/j.cpr.2010.04.007

Ptak, R., 2012. The Frontoparietal Attention Network of the Human Brain: Action, Saliency, and a Priority Map of the Environment. Neurosci. 18, 502-515. doi:10.1177/1073858411409051

Qureshi, S.U., Long, M.E., Bradshaw, M.R., Pyne, J.M., Magruder, K.M., Kimbrell, T., Hudson, T.J., Jawaid, A., Schulz, P.E., Kunik, M.E., 2011. Does PTSD impair cognition beyond the effect of trauma? J. Neuropsychiatry Clin. Neurosci. 23, 1628.

Rabellino, D., Tursich, M., Frewen, P.A., Daniels, J.K., Densmore, M., Théberge, J., Lanius, R.A., 2015. Intrinsic Connectivity Networks in post-traumatic stress disorder during sub- and supraliminal processing of threat-related stimuli. Acta Psychiatr. Scand. doi:10.1111/acps.12418

Rabinak, C.A., Angstadt, M., Welsh, R.C., Kenndy, A.E., Lyubkin, M., Martis, B., Luan Phan, K., 2011. Altered amygdala resting-state functional connectivity in posttraumatic stress disorder. Front. Psychiatry 2. doi:10.3389/fpsyt.2011.00062

Raichle, M.E., 2011. The restless brain. Brain Connect. 1, 3-12. doi:10.1089/brain.2011.0019

Raji, C., Willeumier, K., Taylor, D., 2015. Functional neuroimaging with default mode network regions distinguishes PTSD from TBI in a military veteran population. Brain imaging ....

Ressler, K.J., Mayberg, H.S., 2007. Targeting abnormal neural circuits in mood and anxiety disorders: from the laboratory to the clinic. Nat. Neurosci. 10, 1116-1124. doi:10.1038/nn1944

Reynolds, C., 2002. Comprehensive trail making test (CTMT). Austin, TX Pro-Ed. 
Sadaghiani, S., D’Esposito, M., 2014. Functional Characterization of the CinguloOpercular Network in the Maintenance of Tonic Alertness. Cereb. Cortex. doi:10.1093/cercor/bhu072

Salemink, E., van den Hout, M.A., Kindt, M., 2007. Selective attention and threat: Quick orienting versus slow disengagement and two versions of the dot probe task. Behav. Res. Ther. 45, 607-615. doi:10.1016/j.brat.2006.04.004

Samuelson, K.W., Neylan, T.C., Metzler, T.J., Lenoci, M., Rothlind, J., Henn-Haase, C., Choucroun, G., Weiner, M.W., Marmar, C.R., 2006. Neuropsychological functioning in posttraumatic stress disorder and alcohol abuse. Neuropsychology 20, 716-26. doi:10.1037/0894-4105.20.6.716

Schoorl, M., Putman, P., Van Der Does, W., 2013. Attentional bias modification in posttraumatic stress disorder: a randomized controlled trial. Psychother. Psychosom. 82, 99-105. doi:10.1159/000341920

Seeley, W.W., Menon, V., Schatzberg, A.F., Keller, J., Glover, G.H., Kenna, H., Reiss, A.L., Greicius, M.D., 2007. Dissociable intrinsic connectivity networks for salience processing and executive control. J. Neurosci. 27, 2349-2356. doi:10.1523/JNEUROSCI.5587-06.2007

Semple, W.E., Goyer, P.F., McCormick, R., Donovan, B., Muzic, R.F., Rugle, L., McCutcheon, K., Lewis, C., Liebling, D., Kowaliw, S., Vapenik, K., Semple, M.A., Flener, C.R., Schulz, S.C., 2000. Higher brain blood flow at amygdala and lower frontal cortex blood flow in PTSD patients with comorbid cocaine and alcohol abuse compared with normals. Psychiatry 63, 65-74. doi:Article

Semple, W.E., Goyer, P.F., McCormick, R.A., ComptonToth, B., Morris, E., Donovana, B., Muswick, G., Nelson, D., Garnett, M.L., Sharkoff, J., Leisure, G., Miraldi, F., Schulz, S.C., Compton-Toth, B., Donovan, B.S., 1996. Attention and regional cerebral blood flow in posttraumatic stress disorder patients with substance abuse histories. Psychiatry Res. Neuroimaging 67, 17-28.

doi:http://dx.doi.org/10.1016/0925-4927(96)02735-7

Shallice, T., 1988. Specialisation within the semantic system. Cogn. Neuropsychol.

Shanahan, M., Pennington, B., 2006. Processing speed deficits in attention deficit/hyperactivity disorder and reading disability. J. Abnorm. ....

Shin, L., Whalen, P., Pitman, R., Bush, G., 2001. An fMRI study of anterior cingulate function in posttraumatic stress disorder. Biol. ....

Shin, L.M., Bush, G., Whalen, P.J., Handwerger, K., Cannistraro, P. a., Wright, C.I., Martis, B., Macklin, M.L., Lasko, N.B., Orr, S.P., Pitman, R.K., Rauch, S.L., 2007. Dorsal anterior cingulate function in posttraumatic stress disorder. J. Trauma. Stress 20, 701-712. doi:10.1002/jts.

Shucard, J.L., McCabe, D.C., Szymanski, H., 2008. An event-related potential study of attention deficits in posttraumatic stress disorder during auditory and visual Go/NoGo continuous performance tasks. Biol. Psychol. 79, 223-33. doi:10.1016/j.biopsycho.2008.05.005

Simon, J.R., Wolf, J.D., 1963. Choice reaction time as a function of angular stimulus- 
response correspondence and age. Ergonomics. doi:10.1080/00140136308930679

Sipos, M., Bar- Haim, Y., 2014. Postdeployment threat- related attenion bias interacts with combat exposure to account for PTSD and anxiety symptoms in soldiers. Depress. ....

Sohlberg, M., Mateer, C., 1989. Introduction to cognitive rehabilitation: Theory and practice.

Sonuga-Barke, E.J.S., Castellanos, F.X., 2007. Spontaneous attentional fluctuations in impaired states and pathological conditions: A neurobiological hypothesis. Neurosci. Biobehav. Rev. doi:10.1016/j.neubiorev.2007.02.005

Spencer, A., Faraone, S., 2015. Examining the Association Between Posttraumatic Stress Disorder and Attention-Deficit/Hyperactivity Disorder: A Systematic Review and Meta-Analysis. J. Clin. ....

Sripada, C., Kessler, D., Fang, Y., Welsh, R.C., Prem Kumar, K., Angstadt, M., 2014. Disrupted network architecture of the resting brain in attention-deficit/hyperactivity disorder. Hum. Brain Mapp. 00. doi:10.1002/hbm.22504

Sripada, R., King, A., Garfinkel, S., Wang, X., Sripada, C., Welsh, R., Liberzon, I., 2012. Altered resting-state amygdala functional connectivity in men with posttraumatic stress disorder. J. Psychiatry Neurosci. 37, 241-249. doi:10.1503/jpn.110069

Sripada, R.K., King, a. P., Welsh, R.C., Garfinkel, S.N., Wang, X., Sripada, C.S., Liberzon, I., 2012. Neural Dysregulation in Posttraumatic Stress Disorder: Evidence for Disrupted Equilibrium Between Salience and Default Mode Brain Networks. Psychosom. Med. 74, 904-11. doi:10.1097/PSY.0b013e318273bf33

Stanford, M., Vasterling, J., Mathias, C., 2001. Impact of threat relevance on P3 eventrelated potentials in combat-related post-traumatic stress disorder. Psychiatry ....

Stein, M., Kennedy, C., Twamley, E., 2002. Neuropsychological function in female victims of intimate partner violence with and without posttraumatic stress disorder. Biol. Psychiatry.

Steudte-Schmiedgen, S., 2014. Trauma exposure is associated with increased contextdependent adjustments of cognitive control in patients with posttraumatic stress disorder and healthy controls. Cogn. Affect. ....

Storm, B., White, H., 2010. ADHD and retrieval-induced forgetting: Evidence for a deficit in the inhibitory control of memory. Memory.

Stroop, J.R., 1935. Stroop color word test. J. Exp. Physiol. 643-662. doi:10.1007/978-0387-79948-3

Stuss, D.T., Murphy, K.J., Binns, M.A., Alexander, M.P., 2003. Staying on the job: The frontal lobes control individual performance variability. Brain 126, 2363-2380. doi:10.1093/brain/awg237

Sutker, P., Winstead, D., 1991. Cognitive deficits and psychopathology among former prisoners of war and combat veterans of the Korean conflict. Am. J. ....

Sutker, P.B., Vasterling, J.J., Brailey, K., Allain Jr., A.N., n.d. Memory, attention, and executive deficits in POW survivors: Contributing biological and psychological 
factors.

Swick, D., Honzel, N., Larsen, J., Ashley, V., 2013. Increased response variability as a marker of executive dysfunction in veterans with Post-Traumatic Stress Disorder. Neuropsychologia.

Sylvester, C., Corbetta, M., 2012. Functional network dysfunction in anxiety and anxiety disorders. Trends ... 35, 527-535.

Szymanski, K., Sapanski, L., Conway, F., 2011. Trauma and adhd-Association or diagnostic confusion? A clinical perspective. J. Infant, Child, ....

Thiel, C.M., Zilles, K., Fink, G.R., 2004. Cerebral correlates of alerting, orienting and reorienting of visuospatial attention: An event-related fMRI study. Neuroimage 21, 318-328. doi:10.1016/j.neuroimage.2003.08.044

Thomaes, K., Dorrepaal, E., 2012. on insular and anterior cingulate cortex activation during classic and emotional Stroop interference in child abuse-related complex post-traumatic stress disorder. Psychol. ....

Thomaes, K., Dorrepaal, E., Draijer, N., de Ruiter, M.B., Elzinga, B.M., Sjoerds, Z., van Balkom, A.J., Smit, J.H., Veltman, D.J., 2013. Increased anterior cingulate cortex and hippocampus activation in Complex PTSD during encoding of negative words. Soc. Cogn. Affect. Neurosci. 8, 190-200. doi:10.1093/scan/nsr084

Thomaes, K., Dorrepaal, E., Draijer, N., de Ruiter, M.B., Elzinga, B.M., van Balkom, A.J., Smit, J.H., Veltman, D.J., 2012. Treatment effects on insular and anterior cingulate cortex activation during classic and emotional Stroop interference in child abuse-related complex post-traumatic stress disorder. Psychol. Med. 42, 2337-49. doi:10.1017/S0033291712000499

Trudeau, D., Anderson, J., 1998. Findings of mild traumatic brain injury in combat veterans with PTSD and a history of blast concussion. J. ....

Twamley, E.W., Hami, S., Stein, M.B., 2004a. Neuropsychological function in college students with and without posttraumatic stress disorder. Psychiatry Res. 126, 26574. doi:10.1016/j.psychres.2004.01.008

Twamley, E.W., Hami, S., Stein, M.B., 2004b. Neuropsychological function in college students with and without posttraumatic stress disorder. Psychiatry Res. 126, 26574. doi:10.1016/j.psychres.2004.01.008

Uddo, M., Vasterling, J., Brailey, K., Sutker, P., 1993. Memory and attention in combatrelated post-traumatic stress disorder (PTSD). J. Psychopathol. ....

VanElzakker, M., 2015. The Origin of Concentration Problems in Posttraumatic Stress Disorder.

Vasterling, J., Brailey, K., Constans, J., Sutker, P., 1998. Attention and memory dysfunction in posttraumatic stress disorder. Neuropsychology 12, 125-133.

Vasterling, J.J., Duke, L.M., Brailey, K., Constans, J.I., Allain, A.N., Sutker, P.B., 2002. Attention, learning, and memory performances and intellectual resources in Vietnam veterans: PTSD and no disorder comparisons. Neuropsychology 16, 5-14.

doi:10.1037//0894-4105.16.1.5 
Vaurio, R.G., Simmonds, D.J., Mostofsky, S.H., 2009. Increased intra-individual reaction time variability in attention-deficit/hyperactivity disorder across response inhibition tasks with different cognitive demands. Neuropsychologia 47, 2389-2396.

doi:10.1016/j.neuropsychologia.2009.01.022

Veltmeyer, M., 2005. Integrative assessment of brain and cognitive function in posttraumatic stress disorder. J. Integr. ....

Veltmeyer, M., Clark, C., 2009. Working memory function in post-traumatic stress disorder: an event-related potential study. Clin. ....

Vinogradov, S., Fisher, M., de Villers-Sidani, E., 2012. Cognitive training for impaired neural systems in neuropsychiatric illness. Neuropsychopharmacology 37, 43-76. doi:10.1038/npp.2011.251

Vrana, S., Roodman, A., Beckham, J., 1995. Selective processing of trauma-relevant words in posttraumatic stress disorder. J. Anxiety Disord.

Vythilingam, M., Blair, K., 2007. Biased emotional attention in post-traumatic stress disorder: a help as well as a hindrance? Psychol. ....

Wald, I., Shechner, T., Bitton, S., 2011. Attention bias away from threat during life threatening danger predicts PTSD symptoms at one- year follow- up. Depress. ....

Wechsler, D., 2009. Wechsler Memory Scale-(WMS-IV). New York Psychol. ....

Wechsler, D., 2008. Wechsler adult intelligence scale-Fourth Edition (WAIS-IV). San Antonio, TX NCS Pearson.

Weierich, M.R., Treat, T. a., Hollingworth, A., 2008a. Theories and measurement of visual attentional processing in anxiety, Cognition \& Emotion. doi:10.1080/02699930701597601

Weierich, M.R., Treat, T. a., Hollingworth, A., 2008b. Theories and measurement of visual attentional processing in anxiety, Cognition \& Emotion. doi:10.1080/02699930701597601

Weissman, D.H., Roberts, K.C., Visscher, K.M., Woldorff, M.G., 2006. The neural bases of momentary lapses in attention. Nat. Neurosci. 9, 971-978. doi:10.1038/nn1727

White, S., Costanzo, M., Blair, J., Roy, M., 2015. PTSD symptom severity is associated with increased recruitment of top-down attentional control in a trauma-exposed sample. NeuroImage Clin.

Williams, J.M., Mathews, A., MacLeod, C., 1996. The emotional Stroop task and psychopathology. Psychol. Bull. 120, 3-24. doi:Doi 10.1037/0033-2909.120.1.3

Winstanley, C.A., Eagle, D.M., Robbins, T.W., 2006. Behavioral models of impulsivity in relation to ADHD: translation between clinical and preclinical studies. Clin. Psychol. Rev. 26, 379-95. doi:10.1016/j.cpr.2006.01.001

Wu, J., Ge, Y., Shi, Z., Duan, X., Wang, L., Sun, X., Zhang, K., 2010. Response inhibition in adolescent earthquake survivors with and without posttraumatic stress disorder: a combined behavioral and ERP study. Neurosci. Lett. 486, 117-21. doi:10.1016/j.neulet.2010.07.040

Wu, R.-Z., Zhang, J.-R., Qiu, C.-J., Meng, Y.-J., Zhu, H.-R., Gong, Q.-Y., Huang, X.-Q., 
Zhang, W., 2011. Study on resting-state default mode network in patients with posttraumatic stress disorder after the earthquake. Sichuan Da Xue Xue Bao. Yi Xue Ban 42, 397-400.

Yehuda, R., Golier, J.A., Halligan, S.L., Harvey, P.D., 2004. Learning and memory in Holocaust survivors with posttraumatic stress disorder. Biol. Psychiatry 55, 291295. doi:10.1016/S0006-3223(03)00641-3

Yeo, B.T.T., Krienen, F.M., Sepulcre, J., Sabuncu, M.R., Lashkari, D., Hollinshead, M., Roffman, J.L., Smoller, J.W., Zöllei, L., Polimeni, J.R., Fischl, B., Liu, H., Buckner, R.L., 2011. The organization of the human cerebral cortex estimated by intrinsic functional connectivity. J. Neurophysiol. 106, 1125-65. doi:10.1152/jn.00338.2011

Zalewski, C., Thompson, W., Gottesman, I., 1994. Comparison of Neuropsychological Test Performance in PTSD, Generalized Anxiety Disorder, and Control Vietnam Veterans. Assessment. doi:10.1177/1073191194001002003

Zou, Q., Ross, T.J., Gu, H., Geng, X., Zuo, X.-N., Hong, L.E., Gao, J.-H., Stein, E.A., Zang, Y.-F., Yang, Y., 2013. Intrinsic resting-state activity predicts working memory brain activation and behavioral performance. Hum. Brain Mapp. 34, 320415. doi: $10.1002 / \mathrm{hbm} .22136$ 


\section{Appendix A: Figure Captions}

\section{Figure 1. Intrinsic Connectivity Networks of the Human Brain}

Functional magnetic resonance imaging (fMRI) studies suggest that the brain can be organized into multiple distinct intrinsic connectivity networks, including several "taskpositive" networks - the salience/cinguo-opercular ( $\mathrm{SN}$ ), ventral attention (VAN), and dorsal attention networks (DAN), a "task-negative" network - the default mode network $(\mathrm{DMN})$ and an integration network - the frontoparietal control network, as well as two other commonly described networks discussed in the main text - visual and sensorimotor networks. Abbreviations: PFC, prefrontal cortex; aDLPFC, anterior dorsolateral PFC; dACC, dorsal anterior cingulate cortex; IPS, intraparietal sulcus; IT, inferior temporal cortex; LP, lateral parietal cortex; MCC, middle cingulate cortex; PCC, posterior cingulate cortex; PCG, pre/post central gyrus; pDLPFC, posterior dorsolateral PFC; pOCC, posterior occipital cortex; sgACC, subgenual anterior cingulate cortex; SPL, superior parietal lobule; STG, superior temporal gyrus; TPJ, temporal-parietal junction; VLPFC, ventrolateral PFC. This figure is modified from with permission from Sylvester and Corbetta, 2012.

\section{Figure 2. Schematic of the Attention Network Task (ANT)}

One of four cue types is presented (no, double, center, spatial) followed by one of two target types (congruent, incongruent). The subject's task is to determine the direction that the central arrow is pointing. Differences in reaction time between the condition types reflect the three components of attention (alerting, orienting and conflict monitoring). Figure reproduced with permission from (Jha et al., 2007). 


\section{Appendix B: Tables}

Table 1. Affective Measures of Attention

Name of Task Task Instructions

Dependent Measures

RT to targets in same location as affective - neutral stimulus $=$ attention bias score
Interpretations

Larger score $=$ facilitated orienting or disengagement difficulty

Smaller score $=$ avoidance direction of target

$\begin{array}{ccc}\text { Lexical decision } & \begin{array}{c}\text { Judge series of letters as word or non- } \\ \text { word; some are affective }\end{array} & \begin{array}{c}\text { RT to affective }- \text { neutral words } \\ \text { attention bias score }\end{array}\end{array}$

$\begin{array}{ccc}\text { Lexical decision } & \begin{array}{c}\text { Judge series of letters as word or non- } \\ \text { word; some are affective }\end{array} & \begin{array}{c}\text { RT to affective }- \text { neutral words } \\ \text { attention bias score }\end{array}\end{array}$

$\begin{array}{ccc}\text { Lexical decision } & \begin{array}{c}\text { Judge series of letters as word or non- } \\ \text { word; some are affective }\end{array} & \begin{array}{c}\text { RT to affective }- \text { neutral words } \\ \text { attention bias score }\end{array}\end{array}$

$\begin{array}{ccc}\text { Lexical decision } & \begin{array}{c}\text { Judge series of letters as word or non- } \\ \text { word; some are affective }\end{array} & \begin{array}{c}\text { RT to affective }- \text { neutral words } \\ \text { attention bias score }\end{array}\end{array}$

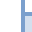

EmotionalStroop

Respond to the color of neutral and affective words
RT to affective - neutral words $=$ interference
Larger score $=$ facilitated orienting or disengagement difficulty

Smaller score $=$ avoidance

\begin{tabular}{|cccc} 
& & Smaller score = avoidance \\
\hline Eye-tracking & View neutral and threatening stimuli & $\begin{array}{c}\text { Stimulus viewed first; } \\
\text { Duration viewed; } \\
\text { Pupil dilation }\end{array}$ & $\begin{array}{c}\text { View threat first/ More time viewing } \\
\text { threat/Greater pupil dilation }= \\
\text { attention bias to threat (facilitated } \\
\text { orienting) }\end{array}$
\end{tabular}

\begin{tabular}{|c|c|c|c|}
\hline Visual search & $\begin{array}{l}\text { Identify if letter string is word or non- } \\
\text { word amongst array of distracters } \\
\text { (neutral, threat and trauma-specific) }\end{array}$ & $\begin{array}{c}\text { RT for threat \& trauma targets - } \\
\text { neutral }\end{array}$ & $\begin{array}{c}\text { Faster RT to trauma \& threat target = } \\
\text { facilitated orienting } \\
\text { Slower RT to neutral target with } \\
\text { trauma distracters = disengagement } \\
\text { difficulty }\end{array}$ \\
\hline $\begin{array}{c}\text { Detection of } \\
\text { Target (DOT) }\end{array}$ & $\begin{array}{l}\text { Two words briefly presented. Target } \\
\text { dot appears in location of one of the } \\
\text { words. Indicate location of target }\end{array}$ & $\begin{array}{c}\text { RT for negative words - neutral } \\
\text { when target is in same (congruent) } \\
\text { or opposite (incongruent) location as } \\
\text { negative word. }\end{array}$ & $\begin{array}{l}\text { Faster RT to congruent negative - } \\
\text { neutral words = facilitated orienting } \\
\text { Slower RT to incongruent negative - } \\
\text { neutral words = disengagement } \\
\text { difficulty }\end{array}$ \\
\hline
\end{tabular}


Table 2. Neural Correlates of Attention Biases in PTSD

\begin{tabular}{|c|c|c|c|c|c|c|}
\hline Task & Contrast & VAN & DAN & SN & DMN & FPCN \\
\hline $\begin{array}{l}\text { Dot-probe } \\
\text { (Fani et al., } \\
\text { 2012) }\end{array}$ & PTSD - TEC on threat -neutral/happy & & $\begin{array}{l}\text { Increased } \\
\text { activity }\end{array}$ & & & $\begin{array}{c}\text { Increased } \\
\text { activity }\end{array}$ \\
\hline $\begin{array}{l}\text { Dot-probe } \\
\text { (Fani et al., } \\
\text { 2012) }\end{array}$ & Correlation with threat bias & & Positive & & & \\
\hline $\begin{array}{c}\text { Dot-probe } \\
\text { (Fani et al., } \\
\text { 2012) } \\
\end{array}$ & Correlation with threat avoidance & Positive & & Positive & & \\
\hline $\begin{array}{c}\text { Working } \\
\text { memory } \\
\text { (Thomaes et al., } \\
\text { 2013) }\end{array}$ & $\begin{array}{c}\text { PTSD - NTC \& TEC on emotional } \\
\text { distracters }\end{array}$ & $\begin{array}{l}\text { Increased } \\
\text { activity }\end{array}$ & & & & \\
\hline $\begin{array}{c}\text { Emotional } \\
\text { Stroop } \\
\text { (Bremner et al., } \\
2004)\end{array}$ & PTSD - NTC on emotion words & & $\begin{array}{l}\text { Decreased } \\
\text { blood flow }\end{array}$ & $\begin{array}{l}\text { Decreased } \\
\text { blood flow }\end{array}$ & & \\
\hline $\begin{array}{l}\text { Emotional } \\
\text { Stroop (Shin et } \\
\text { al., 2001) }\end{array}$ & $\begin{array}{l}\text { PTSD-combat controls on combat- } \\
\text { general threat }\end{array}$ & & $\begin{array}{l}\text { Decreased } \\
\text { activity }\end{array}$ & $\begin{array}{l}\text { Increased } \\
\text { activity }\end{array}$ & & \\
\hline $\begin{array}{c}\text { Emotional } \\
\text { Stroop (White } \\
\text { et al., 2015) }\end{array}$ & $\begin{array}{c}\text { High-low PTSD symptoms to emotional } \\
\text { - neutral stimuli }\end{array}$ & $\begin{array}{l}\text { Increased } \\
\text { activity }\end{array}$ & $\begin{array}{l}\text { Increased } \\
\text { activity }\end{array}$ & $\begin{array}{l}\text { Increased } \\
\text { activity }\end{array}$ & & \\
\hline $\begin{array}{c}\text { Emotional } \\
\text { Stroop (Blair } \\
\text { and } \\
\text { Vythilingam, } \\
\text { 2013) }\end{array}$ & $\begin{array}{c}\text { TEC - PTSD \& NTC on emotional } \\
\text { stimuli }\end{array}$ & & $\begin{array}{l}\text { Increased } \\
\text { activity }\end{array}$ & & & \\
\hline $\begin{array}{c}\text { Emotional } \\
\text { Stroop (Blair } \\
\text { and } \\
\text { Vythilingam, } \\
\text { 2013) }\end{array}$ & $\begin{array}{l}\text { PTSD - NTC \& TEC on emotional } \\
\text { stimuli }\end{array}$ & $\begin{array}{l}\text { Decreased } \\
\text { activity }\end{array}$ & $\begin{array}{l}\text { Decreased } \\
\text { activity }\end{array}$ & & & \\
\hline $\begin{array}{c}\text { Emotional } \\
\text { Oddball (Hayes } \\
\text { et al., 2009) }\end{array}$ & $\begin{array}{c}\text { High - low PTSD symptoms to } \\
\text { emotional distracters }\end{array}$ & $\begin{array}{l}\text { Decreased } \\
\text { activity }\end{array}$ & $\begin{array}{l}\text { Increased } \\
\text { activity }\end{array}$ & $\begin{array}{l}\text { Increased } \\
\text { activity }\end{array}$ & $\begin{array}{l}\text { Increased } \\
\text { activity }\end{array}$ & \\
\hline $\begin{array}{c}\text { Emotional } \\
\text { Oddball } \\
\text { (Hayes et al., } \\
\text { 2009) }\end{array}$ & $\begin{array}{c}\text { High - low PTSD symptoms to neutral } \\
\text { targets }\end{array}$ & & $\begin{array}{l}\text { Decreased } \\
\text { activity }\end{array}$ & $\begin{array}{l}\text { Decreased } \\
\text { activity }\end{array}$ & & \\
\hline $\begin{array}{l}\text { Executive } \\
\text { identification } \\
\text { (Morey et al., }\end{array}$ & $\begin{array}{c}\text { Correlation of combat - civilian } \\
\text { distracter images }\end{array}$ & Positive & & & Positive & \\
\hline
\end{tabular}




\section{Executive} identification

(Morey et al.,

Correlation of executive identification 2008)

with PTSD symptoms

Negative

Negative

Negative

DOT (Khoury-

Malhame and

Correlation with disengagement

Positive

Reynaud, 2011) 
Table 3. Neuropsychological Tests of Attention

\begin{tabular}{|c|c|c|c|c|}
\hline Name of Task & Task Instructions & $\begin{array}{l}\text { Dependent } \\
\text { Measures }\end{array}$ & $\begin{array}{l}\text { Attention } \\
\text { Types } \\
\text { Measured }\end{array}$ & $\begin{array}{c}\text { Other Cognitive Processes } \\
\text { Measured }\end{array}$ \\
\hline $\begin{array}{l}\text { Memory \& } \\
\text { digit span }\end{array}$ & $\begin{array}{l}\text { Immediately repeat a list of items just } \\
\text { seen or heard }\end{array}$ & $\begin{array}{l}\text { Number of items } \\
\text { recalled; RT }\end{array}$ & Sustained & Working memory \\
\hline $\begin{array}{l}\text { Wisconsin } \\
\text { Card Sort }\end{array}$ & $\begin{array}{l}\text { Categorize cards with varying color, } \\
\text { shape and number based on rules that } \\
\text { change throughout task }\end{array}$ & $\begin{array}{l}\text { Perseverations; } \\
\text { errors; categories } \\
\text { achieved }\end{array}$ & Alternating & $\begin{array}{c}\text { Planning; Cognitive flexibility; } \\
\text { Set shifting }\end{array}$ \\
\hline $\begin{array}{l}\text { Tower of } \\
\text { London }\end{array}$ & $\begin{array}{l}\text { Arrange beads on a tower to match } \\
\text { desired goal }\end{array}$ & $\begin{array}{c}\text { Number of moves; } \\
\text { RT; } \\
\text { Number of correct } \\
\text { solutions }\end{array}$ & Alternating & $\begin{array}{c}\text { Planning; Cognitive flexibility; } \\
\text { Set shifting }\end{array}$ \\
\hline $\begin{array}{l}\text { Trail Making } \\
\text { Test Part B } \\
\text { (TMT-B) }\end{array}$ & $\begin{array}{c}\text { Connect alternating numbers and letters } \\
\text { in sequential order }\end{array}$ & RT; Accuracy & $\begin{array}{l}\text { Alternating; } \\
\text { Divided; } \\
\text { Sustained }\end{array}$ & Set shifting \\
\hline Digit Symbol & $\begin{array}{c}\text { Digit-symbol pairs presented. Below } \\
\text { write corresponding symbol to series of } \\
\text { digits }\end{array}$ & RT; Accuracy & $\begin{array}{l}\text { Alternating; } \\
\text { Divided }\end{array}$ & $\begin{array}{l}\text { Processing speed; Set shifting; } \\
\text { Working memory }\end{array}$ \\
\hline $\begin{array}{l}\text { Trail Making } \\
\text { Test Part A } \\
\text { (TMT-A) }\end{array}$ & Connect numbers in sequential order & RT; Accuracy & Selective & Processing speed \\
\hline $\begin{array}{c}\text { Paced } \\
\text { Auditory } \\
\text { Serial Addition } \\
\text { Test (PASAT) }\end{array}$ & $\begin{array}{l}\text { Single digits presented every three } \\
\text { seconds. Add new digit to the one } \\
\text { immediately prior }\end{array}$ & Accuracy & $\begin{array}{l}\text { Alternating; } \\
\text { Divided; } \\
\text { Sustained }\end{array}$ & $\begin{array}{l}\text { Processing speed; } \\
\text { Working memory }\end{array}$ \\
\hline
\end{tabular}


Table 4. Neuropsychological Tests According to Posner Model of Attention

\begin{tabular}{|c|c|c|c|c|}
\hline Name of Task & Task Instructions & $\begin{array}{l}\text { Attention } \\
\text { Types } \\
\text { Measured }\end{array}$ & Dependent Measure & Interpretations \\
\hline \multirow[t]{2}{*}{$\begin{array}{l}\text { Attention } \\
\text { Network Task } \\
\text { (ANT) }\end{array}$} & \multirow{2}{*}{$\begin{array}{c}\text { Indicate direction of central } \\
\text { arrow, which is surrounded by } \\
\text { arrows in the same direction } \\
\text { (congruent) or opposite } \\
\text { (incongruent). Some arrows are } \\
\text { preceded by temporal or spatial } \\
\text { cues }\end{array}$} & $\begin{array}{l}\text { Orienting } \\
\text { Conflict }\end{array}$ & $\begin{array}{c}\text { Orienting }=\text { RT spatial cue }- \\
\text { RT center cue }\end{array}$ & $\begin{array}{c}\text { Larger orienting = difficulty } \\
\text { disengaging attention } \text { or more efficient } \\
\text { use of spatial cues }\end{array}$ \\
\hline & & Monitoring & $\begin{array}{c}\text { Conflict }=\text { RT incongruent }- \\
\text { congruent }\end{array}$ & $\begin{array}{c}\text { Larger conflict }=\text { difficulty resolving } \\
\text { conflict } \text { or more efficient use of } \\
\text { congruent arrows }\end{array}$ \\
\hline
\end{tabular}

\begin{tabular}{|c|c|c|}
\hline & & Alerting \\
\hline Posner Cueing & $\begin{array}{c}\text { Respond a lateral target } \\
\text { immediately after detecting it. } \\
\text { Targets preceded by neutral, valid } \\
\text { and invalid cues }\end{array}$ & $\begin{array}{c}\text { Orienting } \\
\text { Disengageme } \\
\text { nt }\end{array}$ \\
\hline
\end{tabular}

Color words presented that are

Stroop printed in the same or different colored ink. State color of the

$$
\text { print }
$$

\section{RT no cue - neutral $=$ alerting}

RT neutral - valid $=$ orienting

RT invalid - valid $=$ disengagement and reorienting
Larger alerting = difficulty maintaining alertness without a cue or more efficient use of cues

Larger orienting $=$ more efficient use of spatial cues

Larger disengagement and reorienting = more difficulty with these processes
Conflict RT to colors printed in

Monitoring different color - same color
Greater score $=$ greater interference/conflict
Indicate identity of two stimuli

Simon that appear on the left or right side of the screen using left and right buttons
Conflict

Monitoring
RT to button \& screen location is the same - button $\&$ screen location is different
Greater score $=$ greater interference/conflict

Indicate direction of central arrow

Flanker which is surrounded by arrows in the same direction (congruent) or opposite (incongruent)

Greater score $=$ greater interference/conflict

\section{Multisource Interference Task (MSIT)}

\section{Combination of Simon and} Flanker. In a string of three digits, identify the digit that differs from the other two
Conflict Monitoring
RT incongruent-congruent
Greater score $=$ greater interference/conflict 


\begin{tabular}{|c|c|c|c|c|}
\hline $\begin{array}{l}\text { Continuous } \\
\text { Performance } \\
\text { task (CPT) }\end{array}$ & $\begin{array}{c}\text { Repetitive, boredom-inducing } \\
\text { stimuli presented. Respond to } \\
\text { targets but inhibit response to } \\
\text { foils }\end{array}$ & $\begin{array}{l}\text { Alerting; } \\
\text { Orienting; } \\
\text { Conflict } \\
\text { Monitoring }\end{array}$ & RT; accuracy & $\begin{array}{c}\text { Increased RT, RT variability or decrease } \\
\text { accuracy = difficulty with sustained } \\
\text { attention }\end{array}$ \\
\hline Go/No-Go & $\begin{array}{c}\text { Type of CPT. Respond to "go" } \\
\text { trials and inhibit response on "no- } \\
\text { go" trials }\end{array}$ & $\begin{array}{l}\text { Response } \\
\text { Inhibition }\end{array}$ & RT; accuracy & $\begin{array}{l}\text { Increased RT, RT variability or decrease } \\
\text { accuracy = response inhibition difficulty }\end{array}$ \\
\hline Stop-Signal & $\begin{array}{l}\text { Type of CPT. Respond as quickly } \\
\text { as possible to a particular } \\
\text { stimulus feature. On trials with } \\
\text { stop signal, withhold response }\end{array}$ & $\begin{array}{l}\text { Response } \\
\text { Inhibition }\end{array}$ & RT; accuracy & $\begin{array}{l}\text { Increased RT, RT variability or decrease } \\
\text { accuracy = response inhibition difficulty }\end{array}$ \\
\hline Oddball & $\begin{array}{c}\text { In series of repetitive stimuli, } \\
\text { identify target that appears } \\
\text { infrequently }\end{array}$ & Alerting & RT; accuracy & $\begin{array}{c}\text { Increased RT, RT variability or decrease } \\
\text { accuracy }=\text { impaired detection of novel } \\
\text { stimuli }\end{array}$ \\
\hline $\begin{array}{c}\text { Hayling } \\
\text { Sentence } \\
\text { Completion }\end{array}$ & $\begin{array}{l}\text { Part 1: Complete last word of } \\
\text { sentence read by examiner. Part } \\
\text { 2: Complete last word of sentence } \\
\text { read by examiner with nonsense } \\
\text { word }\end{array}$ & $\begin{array}{l}\text { Response } \\
\text { Inhibition }\end{array}$ & $\begin{array}{c}\text { Part } 1=\begin{array}{c}\text { response initiation } \\
\text { speed }\end{array} \\
\text { Part } 2=\text { response suppression }\end{array}$ & $\begin{array}{c}\text { Decreased ability to inhibit real word } \\
\text { answer for part } 2=\text { response inhibition } \\
\text { difficulty }\end{array}$ \\
\hline
\end{tabular}


Table 5. Neural correlates of non-affective attention tasks in PTSD

\begin{tabular}{|c|c|c|c|c|c|c|}
\hline Task & Contrast & SN & VAN & DAN & DMN & FPCN \\
\hline Oddball (Felmingham et al., 2009) & $\begin{array}{l}\text { PTSD - NTC to } \\
\text { targets with } \\
\text { autonomic } \\
\text { arousal - targets } \\
\text { with no arousal }\end{array}$ & $\begin{array}{l}\text { Increased } \\
\text { activity }\end{array}$ & $\begin{array}{l}\text { Decreased } \\
\text { activity }\end{array}$ & $\begin{array}{l}\text { Increased } \\
\text { Activity }\end{array}$ & $\begin{array}{l}\text { Decreased } \\
\text { activity }\end{array}$ & \\
\hline Oddball (Felmingham et al., 2009) & $\begin{array}{l}\text { PTSD - NTC to } \\
\text { targets -baseline }\end{array}$ & $\begin{array}{c}\text { Increased } \\
\text { Activity }\end{array}$ & & & $\begin{array}{l}\text { Increased } \\
\text { activity }\end{array}$ & \\
\hline Go/No-Go (Falconer et al., 2008)* & $\begin{array}{l}\text { PTSD - NTC \& } \\
\text { TEC to NoGo - } \\
\text { Go trials }\end{array}$ & & $\begin{array}{l}\text { Decreased } \\
\text { Activity }\end{array}$ & & & \\
\hline Stroop (Bremner et al., 2004) & $\begin{array}{c}\text { PTSD-TEC on } \\
\text { Stroop - } \\
\text { naming color of } \\
\text { Xs }\end{array}$ & & $\begin{array}{l}\text { Decreased } \\
\text { activity }\end{array}$ & & & \\
\hline Oddball (Bryant et al., 2005)* & $\begin{array}{l}\text { PTSD - NTC on } \\
\text { targets }\end{array}$ & $\begin{array}{l}\text { Increased } \\
\text { Activity }\end{array}$ & $\begin{array}{l}\text { Increased } \\
\text { activity }\end{array}$ & $\begin{array}{l}\text { Decreased } \\
\text { activity }\end{array}$ & $\begin{array}{l}\text { Decreased } \\
\text { activity }\end{array}$ & $\begin{array}{l}\text { Decreased } \\
\text { activity }\end{array}$ \\
\hline MSIT (VanElzakker, 2015) & $\begin{array}{l}\text { PTSD \& NTC } \\
\text { twin pair - TEC } \\
\text { \& NTC twin pair } \\
\text { on incongruent- } \\
\text { congruent }\end{array}$ & $\begin{array}{l}\text { Increased } \\
\text { activity }\end{array}$ & & & & \\
\hline Stroop (Shin et al., 2007) & $\begin{array}{c}\text { PTSD - NTC on } \\
\text { incongruent- } \\
\text { neutral }\end{array}$ & $\begin{array}{l}\text { Increased } \\
\text { activity }\end{array}$ & & & & \\
\hline Stroop (Thomaes et al., 2012) & $\begin{array}{l}\text { PTSD - NTC on } \\
\text { incongruent- } \\
\text { congruent }\end{array}$ & $\begin{array}{l}\text { Increased } \\
\text { activity }\end{array}$ & & & & \\
\hline CPT (Semple et al., 2000) & PTSD - NTC & $\begin{array}{l}\text { Increased } \\
\text { blood blow }\end{array}$ & & & & \\
\hline $\begin{array}{l}\text { Rest (Rabinak et al., 2011; R. Sripada et } \\
\text { al., 2012; R. K. Sripada et al., 2012) }\end{array}$ & $\begin{array}{l}\text { PTSD - TEC } \\
\text { Functional }\end{array}$ & $\begin{array}{l}\text { Increased } \\
\text { SN-SN }\end{array}$ & & $\begin{array}{l}\text { Increased } \\
\text { SN-DAN }\end{array}$ & $\begin{array}{l}\text { Increased } \\
\text { SN-DMN }\end{array}$ & \\
\hline
\end{tabular}


*These studies also found greater visual, sensory and motor processing activation for PTSD - controls. 

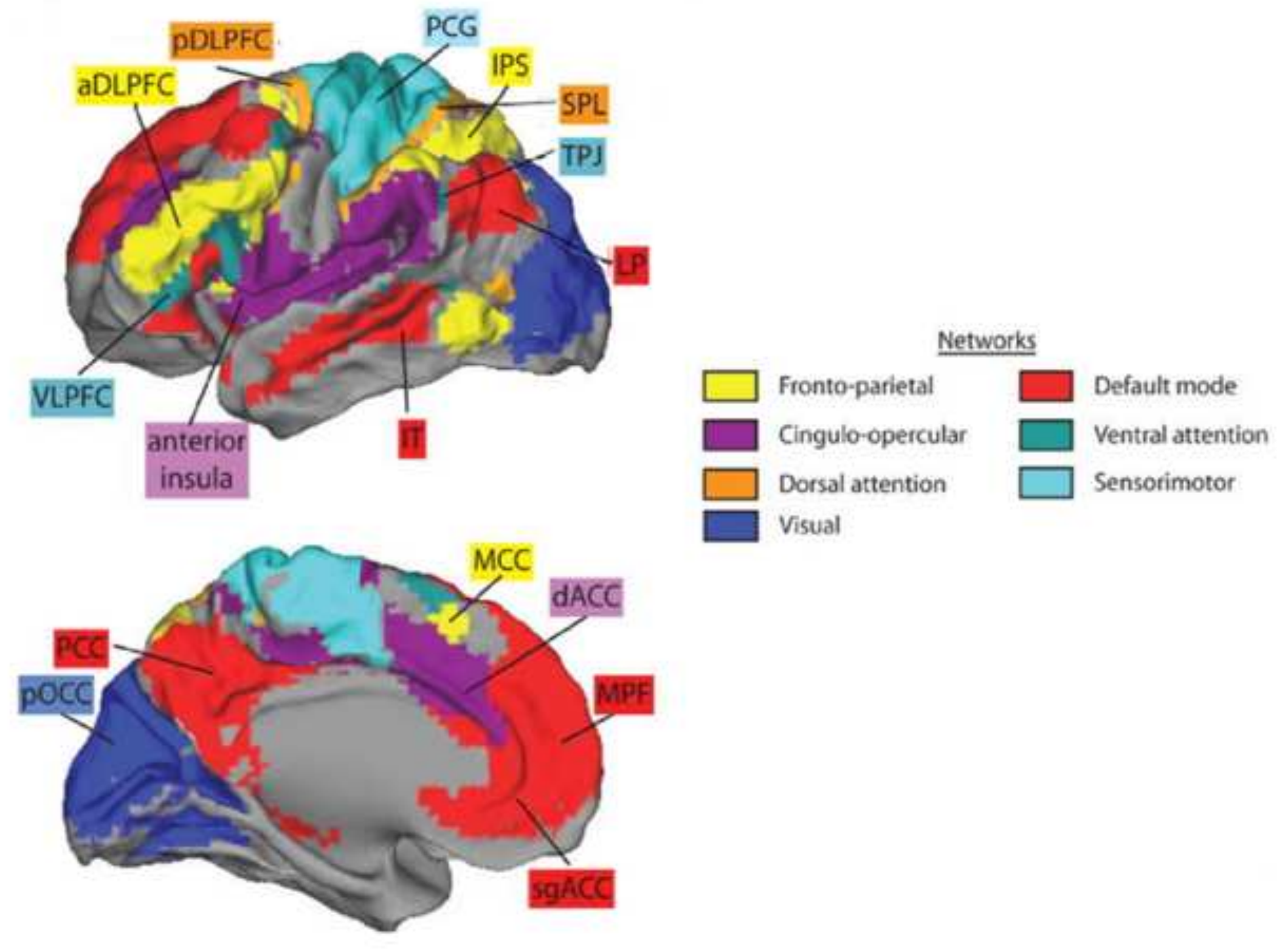

Networks

$\square$ Fronto-parietal $\square$ Default mode

$\square$ Cingulo-opercular $\square$ Ventral attention

$\square$ Dorsal attention $\square$ Sensorimotor

$\square$ Visual 
Trial Sequence

Fixation Cross

Cue

Target

$400-1,600 \mathrm{msec} 100 \mathrm{msec} \quad 400 \mathrm{msec} \quad<1,700 \mathrm{msec}$

Total Trial Duration $=3,500 \mathrm{msec}$

\section{Cue Conditions}

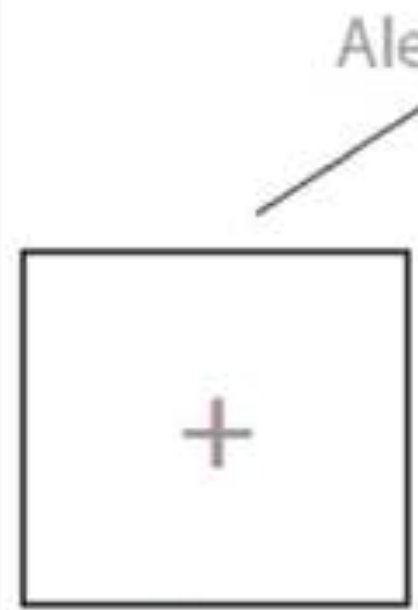

No Cue
Alerting
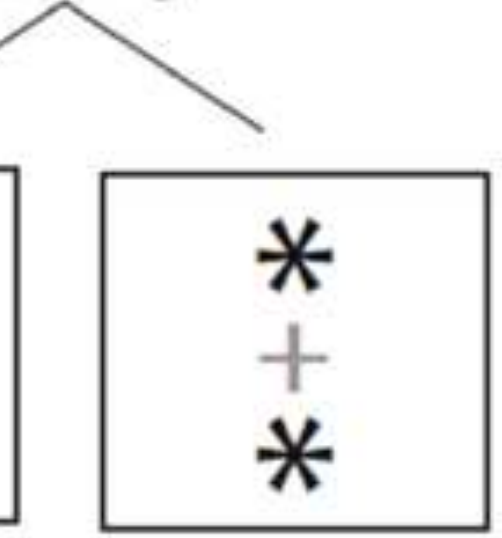

Double

Cue

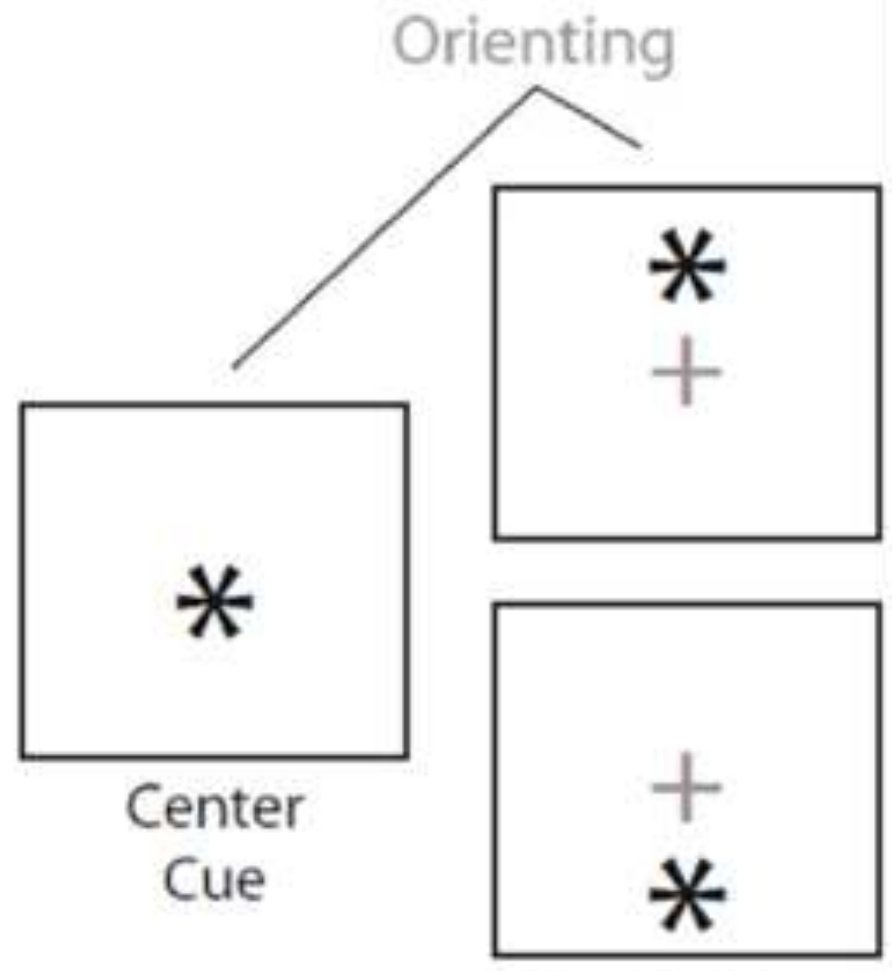

Spatial Cue
Target Conditions

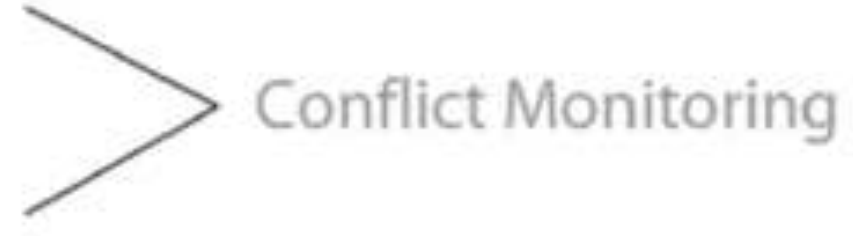

Incongruent Flankers

Congruent Flankers

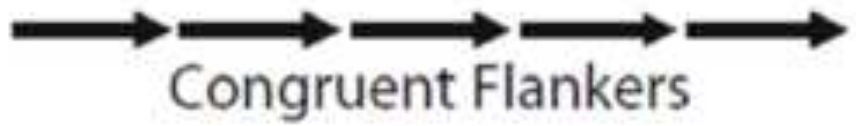

